\title{
Asthma worsenings: Approaches to prevention and management from the Asthma Worsenings Working Group
}

\author{
Meyer Balter MD FRCPC ${ }^{1}$, Pierre Ernst MD², Wade Watson MD MEd FRCPC ${ }^{3}$, Harold Kim MD FRCPC ${ }^{4}$, \\ Lisa Cicutto PhD CAE ${ }^{5}$, Marie-France Beauchesne PharmD CAE ${ }^{6}$, Andrew J Cave MB CCFP FCFP ${ }^{7}$, \\ Alan Kaplan MD CCFP(EM) FCFP ${ }^{8}$, Donna Hogg MSc RN CAE ${ }^{9}$, Andrew Mclvor MD MSc FRCPC ${ }^{10}$, \\ Tom Smiley BScPhm PharmD ${ }^{11}$, Michel Rouleau MD ${ }^{12}$, J Mark FitzGerald MD ${ }^{13}$
}

\begin{abstract}
M Balter, P Ernst, W Watson, et al. Asthma worsenings: Approaches to prevention and management from the Asthma Worsenings Working Group. Can Respir J 2008;15(Suppl B):1B-19B.
\end{abstract}

Most asthma patients prescribed maintenance asthma therapies still experience periods of asthma worsenings characterized by daytime or nighttime symptoms, or an increased need for rescue medication. In fact, these episodes are highly prevalent even in patients with well-controlled disease. Published literature suggests that asthma worsenings likely represent a window of opportunity during which patients could intervene early to prevent exacerbations or further deterioration of asthma symptoms. However, current evidence suggests that most patients fail to respond or to self-manage appropriately during these periods.

To address the issue of asthma worsenings, an interdisciplinary committee of respirologists, allergists, family physicians, pharmacists and certified asthma educators from across Canada developed a practical definition of asthma worsenings and provided approaches to the prevention and management of these episodes based on current literature. To date, combination inhaled corticosteroid/long-acting beta-agonist therapy, particularly single inhaler maintenance and reliever therapy, appears to be an effective strategy for preventing asthma worsenings and exacerbations. Addressing the potential barriers to appropriate patient self-management of asthma worsenings, such as failure to adequately identify and respond to worsenings, low expectations for controlling asthma, low health literacy and poor patient-health care professional communication, are also critical to the successful prevention and management of these episodes. Finally, an interdisciplinary team approach involving patients and their families, certified asthma educators, primary care physicians, pharmacists and specialists is likely to have the greatest impact on the identification, prevention and management of asthma worsenings.

Key Words: Asthma worsenings; Education; Exacerbations; Inhaled corticosteroids; Long-acting beta-agonists
Les aggravations de l'asthme : Les démarches de prévention et de prise en charge du groupe de travail sur les aggravations de l'asthme

La plupart des asthmatiques qui prennent un traitement d'entretien prescrit contre l'asthme vivent tout de même des périodes d'aggravation de l'asthme caractérisées par des symptômes diurnes ou nocturnes ou par un besoin accru de médicaments de rattrapage. En fait, ces épisodes sont hautement prévalents, même chez les patients dont la maladie est bien contrôlée. Selon les publications, les aggravations de l'asthme représenteraient probablement un créneau au cours duquel les patients pourraient intervenir rapidement pour prévenir les exacerbations ou la poursuite de la détérioration des symptômes de l'asthme. Cependant, d'après les données probantes, la plupart des patients ne réagissent pas ou ne se soignent pas convenablement pendant ces périodes.

Pour s'attaquer au problème des aggravations de l'asthme, un comité interdisciplinaire composé de pneumologues, d'allergologues, de médecins de famille, de pharmaciens et d'éducateurs certifiés dans le domaine de l'asthme (ÉCA) du Canada entier ont élaboré une définition pratique des aggravations de l'asthme et proposé des démarches de prévention et de prise en charge de ces épisodes, fondées sur les publications à jour. Jusqu'à présent, l'association de corticoïdes par aérosol et de bêta-agonistes à action prolongée, notamment une thérapie d'entretien et de soulagement unique par inhalation, semble une stratégie de prévention efficace des aggravations et des exacerbations de l'asthme. Pour réussir à prévenir et à prendre en charge ces épisodes, il est également essentiel de s'attaquer aux obstacles potentiels à une prise en charge pertinente des aggravations de l'asthme par les patients, tels que l'incapacité de repérer et de réagir correctement aux aggravations, les faibles attentes quant au contrôle de l'asthme, le peu de connaissances en santé et la mauvaise communication entre les patients et les professionnels de la santé. Enfin, une démarche interdisciplinaire faisant participer les patients et leur famille, les ÉCA, les médecins de premier recours, les pharmaciens et les spécialistes aura probablement les répercussions les plus positives sur le dépistage, la prévention et la prise en charge des aggravations de l'asthme.

of asthma worsenings requiring daily short-acting beta-2 agonist (SABA) therapy at least once per day, with high proportions reporting daytime symptoms, night-time awakenings and hospital admissions due to asthma (4-7). Furthermore, even those with well-controlled disease experience periods of asthma worsenings (4). A recent randomized trial of over 2000 asthma patients who had experienced an exacerbation in the previous year found that despite using moderate to high doses of combination ICS/LABA therapy, episodes of high reliever use on a single day were common and were often associated with a high subsequent risk of an exacerbation (8).

A thma is a variable disease characterized by periods of generally progress, more severe exacerbations. The current man the use of recommended maintenance therapies such as inhaled corticosteroids (ICSs), leukotriene receptor antagonists (LTRAs), or ICS/ long-acting beta-2 agonist (LABA) combinations $(1,2)$. Despite these treatments, asthma control remains suboptimal (3). Surveys of asthma patients have shown that the majority of those prescribed a combination ICS/LABA treatment or ICS therapy alone still experience periods

${ }^{1}$ University of Toronto, Mount Sinai Hospital, Toronto, Ontario; ${ }^{2} \mathrm{McGill}$ University, Montréal, Québec; ${ }^{3}$ Department of Pediatrics, Dalhousie University, Division of Allergy, IWK Health Centre, Halifax, Nova Scotia; ${ }^{4}$ McMaster University, University of Western Ontario, Allergy and Clinical Immunology, Kitchener, Ontario; ${ }^{5}$ Universities of Toronto and Colorado, National Jewish Medical Research Center, Denver, Colorado, USA; ${ }^{6}$ Faculty of Pharmacy, University of Montréal, Hôpital du Sacré-Coeur de Montréal, Montréal, Québec; ${ }^{7}$ Department of Family Medicine, University of Alberta, University of Alberta Hospital, Edmonton, Alberta; ${ }^{8}$ Family Physician Airways Group of Canada, York Central Hospital, Richmond Hill, Ontario; ${ }^{9}$ College and Association of Registered Nurses of Alberta, Edmonton, Alberta; ${ }^{10}$ McMaster University, St Joseph's Healthcare, Firestone Institute for Respiratory Health, Hamilton, Ontario; ${ }^{11}$ Pharmavision Health Consulting Inc, Paris, Ontario; ${ }^{12}$ Laval University, Québec, Québec;

${ }^{13}$ Respiratory Division, University of British Columbia, Vancouver General Hospital, Vancouver, British Columbia

Correspondence and reprints: Dr Meyer Balter, Mount Sinai Hospital, 600 University Avenue, \#6-207, Toronto, Ontario M5G 1 X5.

Telephone 416-586-4800 ext 4663, e-mail mbalter@mtsinai.on.ca 


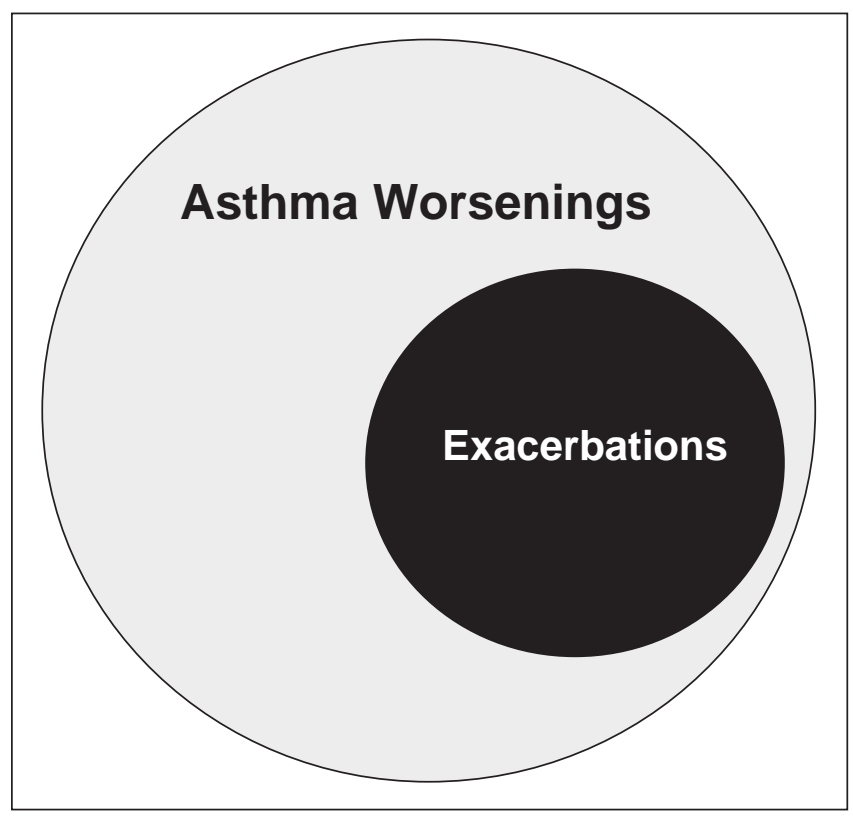

Figure 1) Exacerbations are a subset of asthma worsenings

Although most of these asthma worsenings may not be particularly severe, these episodes have a significant impact on patient quality of life (QOL) (4) as well as potential societal and economic consequences (9-11). In addition, published literature suggests that these worsenings likely represent a window of opportunity during which patients could intervene early to prevent exacerbations or further deterioration of symptoms (12).

In March 2008, an interdisciplinary committee of respirologists, allergists, family physicians, pharmacists and certified asthma educators from across Canada - known as the Asthma Worsenings Working Group (AWWG) - convened to review the current literature surrounding asthma worsenings and, based on their review, provide both a definition of asthma worsenings as well as practical approaches to the prevention and management of these episodes. The present manuscript summarizes these approaches and also provides an overview of asthma worsenings, focusing on the potential impact of these episodes on lung function, QOL, and the overall societal and economic costs of asthma.

\section{DEFINITION OF ASTHMA WORSENING}

There is currently no consensus definition of an asthma worsening. However, definitions found in the literature generally include references to increased SABA use, peak expiratory flow (PEF) changes, and increased daytime and night-time symptoms, including awakenings (4,13-15). Recently, Zhang et al (15) proposed and validated the following definition of asthma worsenings, which includes any one of the following criteria on any study day during treatment: decrease in morning PEF greater than 20\% from baseline; increase in SABA use greater than $70 \%$ above baseline (minimum increase of 2 puffs/day); increase in the symptom score greater than $50 \%$ above baseline; awakenings more than twice in a night; and the occurrence of asthma attacks provoking moderate to marked rescue intervention (oral corticosteroid rescue, visit to physician's office, emergency room [ER] or hospital). The construct validity of this definition was assessed by examining the correlation between the percentage of days with asthma worsenings and global measures of asthma control, changes in asthma specific QOL and changes in forced expiratory volume in $1 \mathrm{~s}\left(\mathrm{FEV}_{1}\right)(15)$.

Evidence suggests that increasing symptoms, increasing need for rescue medications and night-time awakenings are all predictive of asthma worsenings. In their four-week observation of over 2000 asthma patients, McCoy et al (16) found that the relative risk (RR) of both asthma worsenings (defined as episodes of poorly controlled asthma) and exacerbations increased more or less linearly with the presence and intensity of symptoms (as measured by the Two-week Asthma Symptom Score [AS-2]). An analysis of more than 400 severe exacerbations that were documented in the Formoterol and Corticosteroid Establishing Therapy (FACET) study (12) found that the most sensitive index of asthma worsenings was the increased need for rescue SABA therapy in the 14 days preceding the exacerbation, followed by a fall in peak flow and an increase in night-time symptoms.

Based on this evidence as well as the validated definition by Zhang et al (15), the AWWG developed a practical definition that can be used by both healthcare professionals and patients to easily identify periods of asthma worsening (Box).

Definition of asthma worsening as proposed by the AWWG.

Asthma worsening can be defined as an increase in asthma symptoms that are considered "bothersome", that affect normal functioning or sleep, or that lead to an increase in as-needed rescue medication*.

*Two or more inhalations above the baseline mean value

Using this definition, asthma worsenings can be differentiated from both asthma control and exacerbations. Asthma control can be considered an overall state or goal for asthma management that is usually assessed over a time period of at least one week and that is based on numerous criteria including SABA use, daytime and nocturnal symptoms, lung function, restrictions in daily and physical activities, and health care resource use. The concept of asthma control is generally not used or well understood by patients, as evidenced by results from The Reality of Asthma Control (TRAC) in Canada study (13). Almost all (97\%) of the 893 patients included in this study believed that they had controlled asthma; however, only $47 \%$ had controlled disease according to non-pulmonaryfunction-based (ie, symptom and reliever use-based) guideline criteria (13).

An asthma worsening is based on the assessment of current asthma status on a specific day and represents a specific time point in the evolution of asthma that requires immediate action. Because patients generally associate asthma with changes in symptoms, they may be more likely to identify with the concept of asthma worsenings than asthma control. Exacerbations are considered a more severe subset of worsenings (Figure 1) and may be defined as a deterioration in asthma requiring emergency treatment and/or oral corticosteroid therapy. 
TABLE 1

The Reality of Asthma Control (TRAC) study: Asthma worsenings and exacerbations during the past year by asthma control status

\begin{tabular}{lccc}
\hline $\begin{array}{l}\text { Asthma worsening and } \\
\text { exacerbation }\end{array}$ & $\begin{array}{c}\text { Patients with } \\
\text { uncontrolled } \\
\text { asthma }\end{array}$ & $\begin{array}{c}\text { Patients with } \\
\text { controlled } \\
\text { asthma }\end{array}$ & P \\
\hline $\begin{array}{l}\text { Patients with worsening asthma } \\
\text { and exacerbations, n (\%) }\end{array}$ & $474(53)$ & $418(47)$ & \\
$\begin{array}{l}\text { Asthma worsening } \\
\text { Patients who experienced } \\
\text { at least one, \% }\end{array}$ & 95 & 82 & $<0.01$ \\
$\begin{array}{l}\text { Mean duration, days } \\
\text { Asthma exacerbation } \\
\begin{array}{l}\text { Patients who had at least } \\
\text { one urgent office visit, \% }\end{array}\end{array}$ & 13.6 & 8 & $<0.02$ \\
$\begin{array}{l}\text { Patients who had at least } \\
\text { one emergency-room visit, \% }\end{array}$ & 72 & 15 & $<0.01$ \\
$\begin{array}{c}\text { Patients who had at least } \\
\text { one hospitalization, \% }\end{array}$ & 7 & 3 & $<0.01$ \\
\hline
\end{tabular}

*Number of patients adds to 1 less than the total of 893 patients; 1 patient could not be classified because of "don't know" responses or "no" answers to questions on asthma control. Reproduced with permission from reference 17. (C) The College of Family Physicians of Canada

Asthma worsenings can also be differentiated from uncontrolled asthma. In the TRAC study, patients who were considered to have their asthma controlled over time had frequent episodes of worsenings but few exacerbations, while patients with uncontrolled asthma had both frequent worsenings and exacerbations (17). Partridge et al (4) also found that asthma worsenings were common, regardless of level of asthma control.

According to Reddel et al (18), the pattern of deterioration seen in exacerbations, and possibly worsenings as well, is different from that seen during episodes of poor asthma control. For example, the investigators found that peak flow variation was strikingly different during an asthma exacerbation when compared with periods of poor asthma control. During an exacerbation, peak flow fell and then improved linearly over several days, and there was also an impaired response to SABA therapy. Episodes of poor asthma control, on the other hand, were characterized by morning dipping in PEF, wide diurnal variability and an impressive bronchodilator response (18). Therefore, this poor response to SABA treatment appears to delineate an asthma exacerbation from poor control, and may also help differentiate asthma worsenings from poor control.

\section{HIGH PREVALENCE OF ASTHMA WORSENINGS}

Evidence suggests that asthma worsenings are common, even in those patients receiving recommended and established asthma therapies. The TRAC survey $(13,17)$ examined both patient $(n=893)$ and physician $(n=463)$ perceptions and management of asthma worsenings and exacerbations. The definition of an asthma worsening used in this study was more general than the AWWG definition and was defined as a time when asthma was at its worst (most out of control) or when symptoms worsened substantially. An asthma exacerbation was defined as an episode that required acute care (unscheduled physician visit, emergency department visit or overnight hospitalization). Regardless of the background level of control, almost all TRAC patients experienced an asthma worsening in the last year. These periods of asthma worsening were

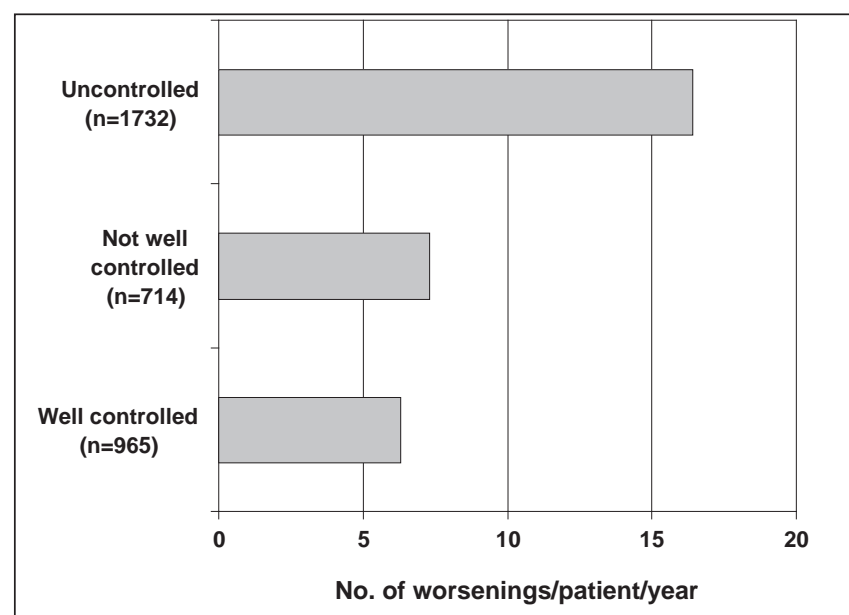

Figure 2) The International Asthma Patient Insight Research (INSPIRE) study: number (No) of asthma worsenings according to level of asthma control. Worsening defined as an occasion when asthma symptoms had become bothersome or intrusive in the past year. The mean number of worsenings for the total population was 11.8 per year. Reproduced with permission from reference 4 . (C) BioMed Central Ltd

significantly longer in patients with uncontrolled versus controlled asthma (Table 1) (17).

The International Asthma Patient Insight Research (INSPIRE) study (4) surveyed 3415 physician-recruited adults (aged 16 years or older) with asthma in 11 countries that were prescribed regular maintenance therapy with an ICS or ICS/ LABA combination. The study examined patients' attitudes toward their asthma management, levels of asthma control, and the frequency and severity of asthma worsenings. Again, the definition of an asthma worsening used in this study was more general than the AWWG definition and was defined as occasions when asthma symptoms had become bothersome or intrusive in the past year. Despite all patients being prescribed regular ICS maintenance therapy and a high proportion of patients using concomitant LABA therapy, only $28 \%$ had well-controlled asthma according to their Asthma Control Questionnaire scores, with $51 \%$ of patients classified as having uncontrolled asthma. In addition, almost $90 \%$ of all patients experienced asthma worsenings during the last year (mean 11.8 per year) (Figure 2). Even patients with well-controlled asthma reported an average of 6.3 worsenings per year. Overall, $42 \%$ of patients rated their most recent asthma worsening as severe, $45 \%$ rated it as moderate and $13 \%$ as mild. On average, patients reported that $27 \%$ of the asthma worsenings experienced in the last year were severe (4).

In a four-week observational study, McCoy et al (16) examined periods of asthma worsenings and exacerbations in 2032 asthma patients (aged three to 64 years). Episodes of asthma worsenings were defined as any one of the following during the study period: peak flow decrease of at least $30 \%$ of personal best; increased rescue medication use (increase in the daily use above the average use reported in the two weeks before randomization); new or increased oral corticosteroid use; or unscheduled health care visit or telephone call to a health care provider. Exacerbations were defined as a 
TABLE 2

Overview of clinical trials examining worsenings (mild exacerbation days/days with symptoms) and severe exacerbations

\begin{tabular}{|c|c|c|c|c|c|}
\hline Study & Description & $\begin{array}{l}\text { Definition of severe } \\
\text { exacerbation }\end{array}$ & $\begin{array}{l}\text { Patients with severe } \\
\text { exacerbations, } \%\end{array}$ & $\begin{array}{l}\text { Definition of asthma } \\
\text { worsening* }\end{array}$ & $\begin{array}{l}\text { Patients with } \\
\text { worsenings, } \%\end{array}$ \\
\hline $\begin{array}{l}\text { Pauwels et } \\
\text { al, } 2003 \\
\text { (19) }\end{array}$ & $\begin{array}{l}\text { 3-year, randomized, } \\
\text { double-blind trial } \\
7241 \text { patients (aged } \\
\text { 5-66 years) with mild } \\
\text { persistent asthma } \\
\text { Bud vs placebo for } \\
3 \text { years }\end{array}$ & $\begin{array}{l}\text { Asthma-related event } \\
\text { requiring hospital } \\
\text { admission or } \\
\text { emergency treatment, } \\
\text { or death due to } \\
\text { asthma }\end{array}$ & $\begin{array}{l}\text { Bud: } 3.3 \\
\text { Placebo: } 5.5\end{array}$ & $\begin{array}{l}\text { Days with symptoms } \\
\text { (opposite of symptom- } \\
\text { free days) }\end{array}$ & $\begin{array}{l}\text { Placebo vs bud: } \\
\text { Year 1: } 15 \% \text { vs } 11 \\
\text { Year 2: } 12 \% \text { vs } 11 \\
\text { Year 3: } 12 \% \text { vs } 10\end{array}$ \\
\hline $\begin{array}{l}\text { Price et al, } \\
2003(20)\end{array}$ & $\begin{array}{l}\text { 16-week, double-blind, } \\
\text { randomized, parallel group, } \\
\text { non-inferiority study } \\
889 \text { adults (aged } \\
\text { 15-75 years) with } \\
\text { inadequately controlled }\end{array}$ & $\begin{array}{l}\text { A day with a }>20 \% \text { decrease } \\
\text { from baseline in morning } \\
\text { PEF; an increase in SABA } \\
\text { use of }>70 \% \text { (minimum } \\
\text { increase of two puffs), or an } \\
\text { increase in symptom score }\end{array}$ & $\begin{array}{l}\text { Mont + bud: } 1.6 \\
\text { Double-dose bud: } 2.3\end{array}$ & $\begin{array}{l}\text { Opposite of asthma-free } \\
\text { days (defined as any day } \\
\text { free of oral corticosteroid } \\
\text { use, emergency care, noc- } \\
\text { turnal awakenings, with } \\
\text { use of <2 puffs of SABA) }\end{array}$ & $\begin{array}{l}\text { Mont + bud: } 13.3 \\
\text { Double-dose bud: } 17.8\end{array}$ \\
\hline
\end{tabular}

O'Byrne et al, 1-year, randomized,

2005 (14) double-blind trial

2760 patients (aged

4-80 years) treated with ICS

and a history of $\geq 1$ exacer-

bation in the last year

Treatment groups:

Bud/form M + R

Bud/form + SABA

Bud + SABA

Lundbäck et 1-year, randomized, double-

al, $2006 \quad$ blind parallel-group study

(21) 282 patients (aged

18-70 years) with mild

to moderate asthma

Treatment groups:

Salm/flutic

Flutic alone

Salm alone

Rabe et al, 12-month, randomized, double-

2006 (22) blind, parallel-group study

3394 asthma patients (aged

$\geq 12$ years) using bud/form

maintenance therapy

Designed to evaluate the addi-

tional benefits of the following

as-needed therapies:

Bud/form

Form

Terbut

Boulet et al, 12-week, randomized,

2007 (24) open-label study

474 patients (aged

12-75 years) with moderate,

persistent asthma

of $\geq 50 \%$, or an asthma

attack (worsening of asthma

requiring an unscheduled

physician or ED visit

admission to hospital, or

treatment with ora

corticosteroids)

Deterioration in asthma

resulting in hospitalization/

ED treatment, oral steroid

treatment or morning PEF

$\leq 70 \%$ of baseline on

2 consecutive days

Bud/form M + R: 16

Mild exacerbation days:

Bud/form M + R: 17

Bud/form + SABA: 27

any day with awakening

Bud + SABA: 28

caused by asthma, with

Bud/form + SABA: 23

as-needed medication

use of $\geq 2$ inhalations

above baseline mean

value, or with morning

PEF $\leq 80 \%$ of baseline

mean value

Deterioration in asthma requiring an increase in rescue medication use over that used during run-in period of $>6$ puffs/day for $\geq 2$ consecutive days, or an increase of $\geq 2$ doses/day in regular inhaled medication (study medication or additional ICS) for $\geq 2$ days by the patient's own decision, or

$\geq 2$ days when asthma symptoms prevented work or normal activities

$\%$ of patients experienc- Days with symptoms ing $\geq 2$ exacerbations: (opposite of symptomSalm/flutic: 4.2 free days)

Bud + SABA: 20

Flutic: 17.4

Salm: 40.0

Deterioration in asthma resulting in emergency treatment or hospitalization or the need for oral steroids $\geq 3$ days

Bud/form prn: 12

Form prn: 17

Terbut prn: 22

Deterioration of asthma requiring treatment with oral steroids

Ciclesonide: 1.3

Flutic: 2.1
Mild exacerbation days: any night with an awakening due to asthma, morning PEF $\geq 20 \%$ below baseline or as-needed medication use of $\geq 2$ inhalations in $24 \mathrm{~h}$ above baseline
Days with asthma symptoms and with rescue medication use
Bud/form prn: 74

Form prn: 77

Terbut prn: 78

flutic: 33

Flutic: 32.1

Salm: 55.5

Ciclesonide vs flutic 
TABLE 2 - CONTINUED

Overview of clinical trials examining worsenings (mild exacerbation days/days with symptoms) and severe exacerbations

\begin{tabular}{|c|c|c|c|c|c|}
\hline Study & Description & $\begin{array}{c}\text { Definition of severe } \\
\text { exacerbation }\end{array}$ & $\begin{array}{c}\text { Patients with severe } \\
\text { exacerbations, } \%\end{array}$ & $\begin{array}{c}\text { Definition of asthma } \\
\text { worsening* }\end{array}$ & $\begin{array}{c}\text { Patients with } \\
\text { worsenings, } \%\end{array}$ \\
\hline $\begin{array}{l}\text { Bousquet et } \\
\text { al, } 2007 \text { (8) }\end{array}$ & $\begin{array}{l}\text { 6-month, double-blind, } \\
\text { randomized study } \\
2309 \text { patients (aged } \geq 12 \text { years) } \\
\text { with symptomatic asthma } \\
\text { (FEV }_{1} \geq 50 \% \text { predicted) who had } \\
\text { experienced an asthma exacer- } \\
\text { bation in the previous year } \\
\text { Treatment groups: } \\
\text { Bud/form } \mathrm{M}+\mathrm{R} \\
\text { Salm/flutic + SABA }\end{array}$ & $\begin{array}{l}\text { Deterioration in asthma } \\
\text { leading to hospitalization/ } \\
\text { ED treatment and/or oral } \\
\text { corticosteroid treatment } \\
\geq 3 \text { days }\end{array}$ & $\begin{array}{l}\text { Bud/form M + R: } 9.4 \\
\text { Salm/flutic + SABA: } 11.3\end{array}$ & $\begin{array}{l}\text { Opposite of asthma control } \\
\text { days (defined as a day } \\
\text { and night with no asthma } \\
\text { symptoms, no awakenings } \\
\text { due to asthma and no as- } \\
\text { needed medication use) }\end{array}$ & $\begin{array}{l}\text { Before treatment: } \\
\text { Bud/form M + R: } 93.7 \\
\text { Salm/flutic + SABA: } \\
94.2 \\
\text { On treatment: } \\
\text { Bud/form M + R: } 56 \\
\text { Salm/flutic + SABA: } \\
55.1\end{array}$ \\
\hline $\begin{array}{l}\text { Kuna et al, } \\
2007 \text { (23) }\end{array}$ & $\begin{array}{l}\text { 6-month, randomized, double- } \\
\text { blind study } \\
3335 \text { symptomatic adults and } \\
\text { adolescents ( } \geq 12 \text { years) with } \\
\text { asthma } \\
\text { Treatment groups: } \\
\text { Bud/form M + R } \\
\text { Bud/form + SABA } \\
\text { Salm/flutic + SABA }\end{array}$ & $\begin{array}{l}\text { Deterioration in asthma } \\
\text { resulting in hospitalization } \\
\text { or ED treatment, or need } \\
\text { for oral steroids for } \geq 3 \text { days }\end{array}$ & $\begin{array}{l}\text { Bud/form M + R: } 9 \\
\text { Bud/form + SABA: } 11 \\
\text { Salm/flutic + SABA: } 12\end{array}$ & $\begin{array}{l}\text { Two consecutive mild exac- } \\
\text { erbation days (defined as } \\
\text { a day with any one of the } \\
\text { following: morning PEF } \\
\geq 20 \% \text { below baseline, } \\
\text { daily as-needed medica- } \\
\text { tion use } \geq 2 \text { inhalations } \\
\text { above baseline or a night } \\
\text { with an asthma-related } \\
\text { awakening) }\end{array}$ & $\begin{array}{l}\text { Bud/form M + R: } 61 \\
\text { Bud/form + SABA: } 63 \\
\text { Salm/flutic + SABA: } 59 \\
\text { Average number of } \\
\text { worsenings/patient/ } \\
6 \text { months: } \\
\text { Bud/form M + R: } 27 \\
\text { Bud/form + SABA: } 29 \\
\text { Salm/flutic + SABA: } 27\end{array}$ \\
\hline $\begin{array}{l}\text { Bateman et } \\
\text { al, } 2008 \\
(25)\end{array}$ & $\begin{array}{l}\text { 6-month, randomized, } \\
\text { open-label, parallel-group } \\
\text { study } \\
528 \text { patients (aged } \geq 12 \text { years } \\
\text { and }<80 \text { years) with a } 6 \text {-month } \\
\text { history of bronchial asthma } \\
\text { Ciclesonide vs flutic }\end{array}$ & $\begin{array}{l}\text { Worsening asthma } \\
\text { symptoms or a } \\
\text { reduction in lung } \\
\text { function requiring } \\
\text { treatment with oral } \\
\text { steroids }\end{array}$ & $\begin{array}{l}\text { Ciclesonide: } 2.3 \\
\text { Flutic: } 2.5\end{array}$ & $\begin{array}{l}\text { Days with asthma symp- } \\
\text { toms and with rescue } \\
\text { medication use }\end{array}$ & $\begin{array}{l}\text { Ciclesonide: } 26 \\
\text { Flutic: } 27\end{array}$ \\
\hline
\end{tabular}

*As per Asthma Worsenings Working Group considerations. Bud Budesonide; ED Emergency department; FEV 1 Forced expiratory volume in 1 s; flutic Fluticasone; form Formoterol; M + R Maintenance plus relief; mont Montelukast; PEF Peak expiratory flow; SABA Short-acting beta-2 agonist; salm Salmeterol; terbut Terbutaline; vs Versus

subset of these worsenings and were characterized by either new or increased use of oral corticosteroids or by an unscheduled health care visit for asthma. During the 28-day follow-up, $43.2 \%$ of participants had at least one asthma worsening. Approximately $24.3 \%$ of these episodes were characterized by the increased use of rescue medications, while nearly $15 \%$ were associated with exacerbations (16).

During the AWWG's review of the literature surrounding asthma worsenings, the group noted that the definitions of mild exacerbation days or days with symptoms in various clinical trials of asthma therapies were similar to the group's definition of an asthma worsening (8,14,19-25). When considering these mild exacerbation days/days with symptoms as asthma worsenings, the group concluded that worsenings are highly prevalent even in those patients receiving guideline-recommended therapies in the setting of clinical trials. Table 2 provides a brief overview of the definitions and results related to asthma worsenings and exacerbations noted in each of these trials. Given their high prevalence, asthma worsenings warrant immediate identification as well as strategies for prevention and management.

\section{ASTHMA WORSENINGS: A WINDOW OF OPPORTUNITY}

Not only are asthma worsenings common, but evidence also suggests that worsenings often precede exacerbations and may represent immediate action points for the prevention of exacerbations or further deterioration of symptoms (12). In a study by Bousquet et al (8), days with an increased number of as-needed inhalations (more than two, four, six or eight inhalations/day) were used to identify periods of asthma worsening. Regardless of treatment group, patients who had used more than four reliever doses on any single day were almost twice as likely to experience a subsequent severe exacerbation in the days following the episode of worsening, suggesting that asthma worsenings may predict the occurrence of asthma exacerbations.

In the INSPIRE study (4), most patients reported experiencing early warning signs, primarily symptoms of breathlessness, before an asthma worsening. The mean period from the occurrence of these early signs to the peak of an asthma worsening was approximately five days and was followed by a recovery period of similar length (Figure 3). This time period from the onset of initial symptoms to an exacerbation or peak in symptom worsening was also noted in an analysis of over 400 severe exacerbations that were documented in the FACET study (12). The results of this analysis showed that PEF decreased and patientreported asthma symptom scores increased gradually in the days before an asthma exacerbation, returning to previous levels in the days following the event (Figure 4) (12). These findings suggest that asthma worsenings represent a window of opportunity during which patients can intervene early by increasing their anti-inflammatory medication to possibly prevent an exacerbation or further deterioration of asthma symptoms.

\section{CAUSES OF ASTHMA WORSENINGS}

Like exacerbations, asthma worsenings are most likely caused by airway inflammation resulting from exposure to a viral illness or allergen (27). The pattern of airway inflammation differs 


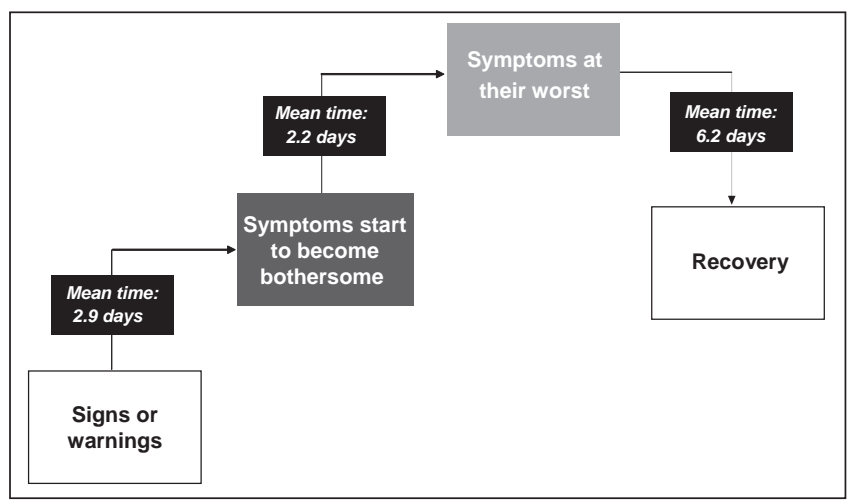

Figure 3) Mean length of time between stages leading up to and beyond a worsening. Base: all respondents who noticed signs or warnings $(n=2332) /$ all respondents $(n=3415)$. Patients were asked about length of time between initial signs or warnings and when symptoms started to become bothersome, between bothersome symptoms and when symptoms were at their worst, and between symptoms at their worst and recovery. Adapted from reference 4

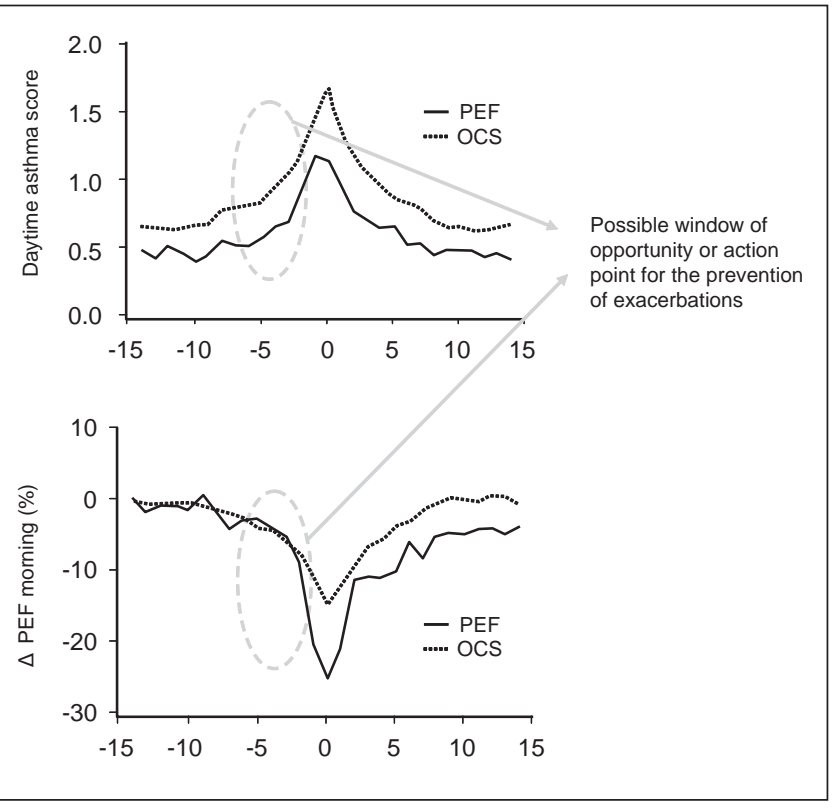

Figure 4) Changes in daytime asthma score and morning peak expiratory flow (PEF) in relation to whether the exacerbation was diagnosed by the need for oral steroids or by a fall in PEF. The values for evening PEF and nocturnal symptoms (not shown) were similar. Note: Changes in peak flow rates and symptoms generally move together, such that reductions in PEF are associated with increased symptoms and vice versa. However, most action plans are symptom-based and do not take into account PEF changes. OCS Oral corticosteroids. Adapted from reference 12

according to the environmental trigger. For example, virusinduced exacerbations are characterized by neutrophilic infiltration, while allergen-induced asthma may stimulate interleukin (IL)-5 mediated processes as well as other events to attract eosinophils. Both pathways, however, lead to inflammatory cell activation and oxidative stress (Figure 5) (27).

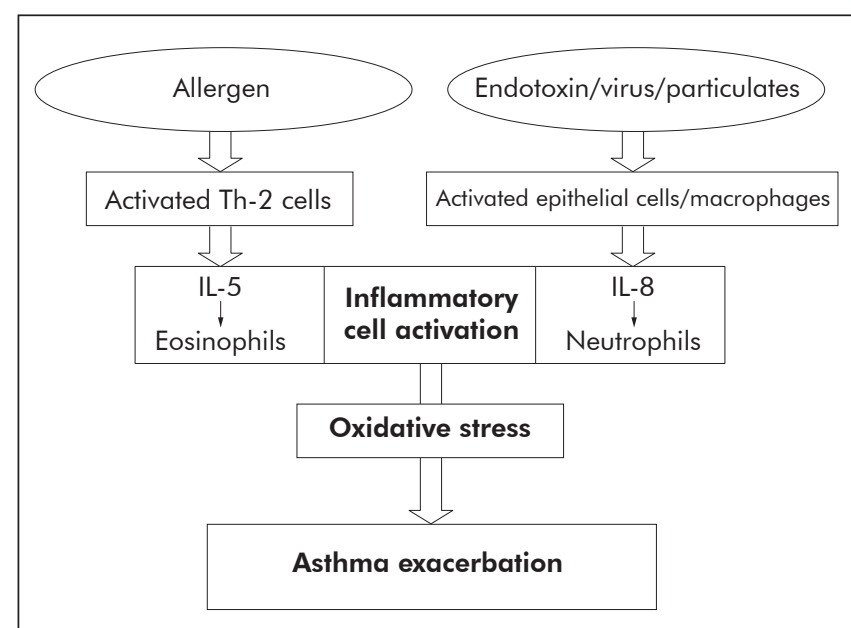

Figure 5) Environmental exposures that trigger asthma exacerbations generate specific cytokine response patterns that result in granulocyte infiltration, activation, and oxidative stress. IL Interleukin; Th-2 Type 2 helper T cell. Reproduced with permission from reference 27. (C) British Thoracic Society

\section{TABLE 3}

Main characteristics of patients with slow-onset and sudden-onset acute asthma

\begin{tabular}{|c|c|}
\hline Type 1: Slow progression & Type 2: Sudden progression \\
\hline Slow-onset acute asthma & $\begin{array}{l}\text { Sudden-onset, asphyxic, brittle or } \\
\text { hyperacute asthma }\end{array}$ \\
\hline $\begin{array}{l}\text { Progressive deterioration: }>6 \text { h } \\
\text { (usually days or weeks) }\end{array}$ & Rapid deterioration: <6 h \\
\hline $\begin{array}{l}80 \% \text { to } 90 \% \text { who presented to an } \\
\text { emergency department }\end{array}$ & $\begin{array}{l}10 \% \text { to } 20 \% \text { who presented to an } \\
\text { emergency department }\end{array}$ \\
\hline Female predominance & Male predominance \\
\hline $\begin{array}{l}\text { More likely to be triggered by an } \\
\text { upper respiratory tract infection }\end{array}$ & $\begin{array}{l}\text { More likely to be triggered by } \\
\text { respiratory allergens, exercise and } \\
\text { psychosocial issues }\end{array}$ \\
\hline $\begin{array}{l}\text { Less severe obstruction at } \\
\text { presentation }\end{array}$ & $\begin{array}{l}\text { More severe obstruction at } \\
\text { presentation }\end{array}$ \\
\hline $\begin{array}{l}\text { Slow response to treatment and } \\
\text { higher hospital admissions }\end{array}$ & $\begin{array}{l}\text { Rapid response to treatment and } \\
\text { lower hospital admissions }\end{array}$ \\
\hline Airflow inflammation mechanism & $\begin{array}{l}\text { Bronchospastic mechanism of } \\
\text { deterioration }\end{array}$ \\
\hline
\end{tabular}

Reproduced with permission from reference 26. (C) The American College of Chest Physicians

The type of trigger may also impact the type of exacerbation or asthma worsening experienced by the patient: sudden-onset or slow-onset $(26,28)$. According to Rodrigo et al (26), slowonset exacerbations are the most common type, occurring in approximately $80 \%$ to $90 \%$ of adults with acute asthma who present to an emergency department. They are characterized by progressive clinical and functional deterioration which occurs over many hours, days, or even weeks (Table 3). In these cases, upper respiratory tract infections are frequently the triggers and these patients exhibit a slow response to therapy. Rapid- or sudden-onset attacks are less common and are characterized by rapid development of airway obstruction (within $3 \mathrm{~h}$ to $6 \mathrm{~h}$ ). Respiratory allergens, exercise, and psychosocial stress are the most frequent triggers of these types of exacerbations. Patients experiencing these sudden-onset exacerbations also exhibit a more rapid and complete response to treatment (26). This may 


\section{TABLE 4}

Mechanisms of inflammation

\begin{tabular}{ll}
\hline Steroid-sensitive changes & LABA-sensitive changes \\
\hline Increased eosinophils & Airway smooth muscle contraction \\
Increased mast-cell production & Plasma exudation \\
Increased Th-2 cells & Mast-cell release \\
Increased blood flow & Increased neutrophils \\
\hline
\end{tabular}

LABA Long-acting beta-2 agonist; Th-2 Type 2 helper T cell. Adapted from reference 29

reflect the fact that this type of rapid deterioration in asthma may be a feature of poorly controlled asthma where the response to bronchodilators is often marked (18). It is also likely that these episodes of rapid deterioration are not primarily inflammatory, but rather the result of an acute episode of bronchoconstriction, hence the rapid response to bronchodilators.

Regardless of the trigger factor or type of exacerbation, therapies addressing the various mechanisms of inflammation will be critical for the prevention of worsenings and their possible progression to an exacerbation. Barnes (29) recently classified the mechanisms of inflammation into two categories - those mechanisms that are sensitive to ICS therapy and those that are sensitive to LABA therapy (Table 4). These mechanisms and their varying susceptibility to ICS and LABA therapy highlight the importance of combination controller treatment and the need to understand the phenotypes of airway inflammation in the prevention of asthma exacerbations, and possibly asthma worsenings.

\section{IMPACT OF ASTHMA WORSENINGS}

\section{Impact on lung function}

There is some direct and indirect evidence suggesting that exacerbations, and possibly worsenings, may lead to a decline in lung function. Bai et al (30) examined the effect of severe exacerbations on the progression of airway obstruction in 93 nonsmoking patients with moderate-to-severe asthma before ICS treatment. Patients with frequent exacerbations (exacerbation rate above the median of 0.1 /year) were found to have a significantly larger annual decline in $\mathrm{FEV}_{1}(31.5 \mathrm{~mL} /$ year, $95 \%$ CI 18.2 to $44.8 ; \mathrm{P}=0.03)$ compared with patients with infrequent exacerbations $(14.6 \mathrm{~mL} /$ year, $95 \%$ CI 1.9 to 27.3; Figure 6). After a median follow-up of 11 years, $\mathrm{FEV}_{1}$ was $64 \pm 18.9 \%$ predicted $(2.08 \pm 0.72 \mathrm{~L})$ in the group with frequent exacerbations compared with $77.2 \pm 19.1 \%$ predicted $(2.69 \pm 0.93 \mathrm{~L})$ in those with infrequent exacerbations $(\mathrm{P}=0.0002)$. Exacerbation rate significantly predicted an excess decline in $\mathrm{FEV}_{1}$, such that one severe exacerbation per year was associated with a $30.2 \mathrm{~mL}$ greater annual decline in $\mathrm{FEV}_{1}$. The authors concluded that these intermittent periods of increased airway inflammation were associated with a more rapid decline in lung function (30).

Evidence from trials examining the effects of ICS therapy on lung function decline also provide indirect evidence that intermittent periods of asthma worsening or exacerbations may impact lung function. The Inhaled Steroid Treatment As Regular Therapy in Early Asthma (START) study (31) examined the impact of low-dose inhaled budesonide on lung function in over 7000 patients (aged five to 66 years) with persistent asthma of less than two years' duration. Treatment with budesonide significantly improved prebronchodilator and postbronchodilator $\mathrm{FEV}_{1} \%$ predicted, and reduced the mean decline from baseline

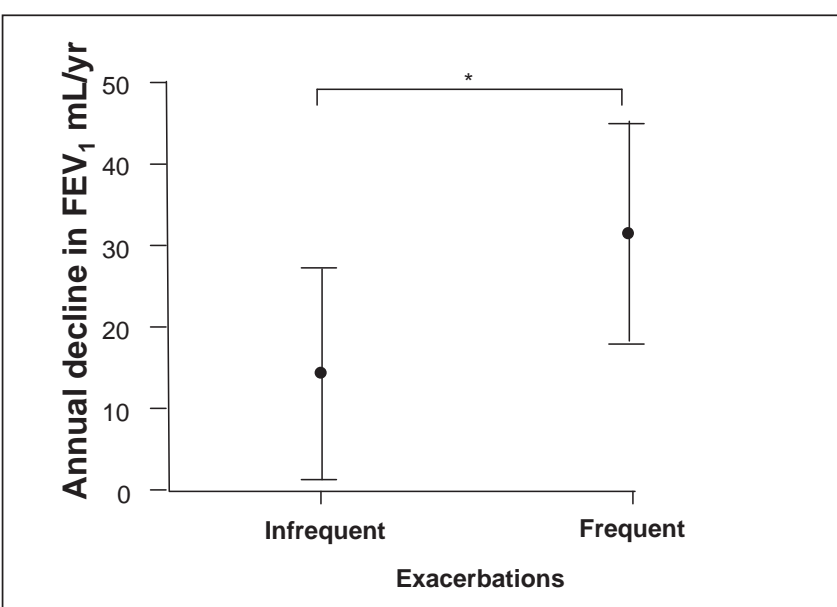

Figure 6) Estimated annual decline in forced expiratory volume in $1 \mathrm{~s}\left(\mathrm{FEV}_{1}\right)$ in patients with infrequent or frequent asthma exacerbations. The analysis was adjusted for sex, height, the first available FEV after 25 years of age and the use of oral corticosteroids. The error bars represent $95 \% \mathrm{CIs} . * \mathrm{P}<0.05$. This figure has been reproduced from reference 30 with the permission of the European Respiratory Society. The article has not been reviewed by European Respiratory Society prior to release, therefore the European Respiratory Society may not be responsible for any errors, omissions or inaccuracies, or for any consequences arising there from, in the content

for postbronchodilator $\mathrm{FEV}_{1}$ at both one year and three years $(0.62 \%$ and $1.79 \%$ for budesonide, and $2.11 \%$ and $2.68 \%$ for placebo, respectively). These declines were greater in male patients, active smokers and patients older than 18 years of age; the smallest treatment effects were noted in adolescents (31).

Using data from the Copenhagen City Heart Study, Lange et al (32) observed a reduction in $\mathrm{FEV}_{1}$ decline over 10 years in patients with adult asthma (older than 30 years of age) who were using ICS therapy throughout the observation period. Overall, ICS therapy reduced the annual decline in $\mathrm{FEV}_{1}$ by $23 \mathrm{~mL} /$ year when compared with asthma patients not using ICSs, and this benefit was of similar magnitude in smokers and nonsmokers.

Since numerous clinical trials have confirmed that ICS therapy reduces the risk of exacerbations $(19,33,34)$, the START study and Copenhagen City Heart study provide indirect evidence that exacerbations may be related to loss of lung function over time, and that prevention of exacerbations may prevent or reverse lung function decline. However, it should be noted that two studies involving children found no evidence that ICS therapy reduces lung function decline and inflammation $(35,36)$. There also appears to be sex-related differences with regard to the impact of ICS therapy on lung function. The results of a 23-year follow-up study of patients with moderate to severe asthma in the Netherlands showed that ICS treatment was associated with a reduction in $\mathrm{FEV}_{1}$ decline only in men who had smoked less than five pack-years. This effect was dose dependent and was not present in women or in men with greater than five pack-years history of smoking at follow-up (37). The lack of effect of ICS on FEV decline in $_{1}$ children and the inconsistent observations in women require further investigation. 


\begin{tabular}{|c|c|c|c|}
\hline $\begin{array}{l}\text { Use of health care } \\
\text { resources }\end{array}$ & $\begin{array}{l}\text { Appropriate } \\
\text { use }(n=4671)\end{array}$ & $\begin{array}{c}\text { Inappropriate } \\
\text { use }(n=763)\end{array}$ & $\mathbf{P}$ \\
\hline \multicolumn{4}{|l|}{ Hospital resources } \\
\hline \multicolumn{4}{|l|}{ Hospital admissions } \\
\hline $\begin{array}{l}\text { Patients admitted at least } \\
\text { once, } \mathrm{n}(\%)\end{array}$ & $257(5.5)$ & $64(8.4)$ & 0.002 \\
\hline Admissions per patient & $0.07 \pm 0.34$ & $0.11 \pm 0.42$ & 0.006 \\
\hline \multicolumn{4}{|l|}{ Urgent admissions } \\
\hline $\begin{array}{l}\text { Patients with at least } \\
1 \text { urgent admission, n (\%) }\end{array}$ & $154(3.3)$ & $44(5.8)$ & 0.001 \\
\hline $\begin{array}{l}\text { Urgent admissions per } \\
\text { patient }\end{array}$ & $0.04 \pm 0.26$ & $0.08 \pm 0.33$ & 0.005 \\
\hline \multicolumn{4}{|l|}{ Prescribing physicians* } \\
\hline $\begin{array}{l}\text { "Prescribing physicians" seen per } \\
\text { patient }\end{array}$ & $1.4 \pm 0.7$ & $1.8 \pm 1.4$ & $<0.001$ \\
\hline $\begin{array}{l}\text { Prescriptions }{ }^{\dagger} \text { per } \\
\text { physician }\end{array}$ & $2.5 \pm 1.5$ & $5.2 \pm 4.2$ & $<0.001$ \\
\hline Prescriptions per patient & $3.3 \pm 1.9$ & $7.5 \pm 4.9$ & $<0.001$ \\
\hline \multicolumn{4}{|l|}{ All physicians $^{\ddagger}$} \\
\hline Physicians seen per patient & $5.1 \pm 4.2$ & $4.8 \pm 4.3$ & 0.16 \\
\hline Visits per physician & $3.2 \pm 3.0$ & $3.9 \pm 3.8$ & $<0.001$ \\
\hline $\begin{array}{l}\text { Visits to all physicians per } \\
\text { patient }\end{array}$ & $14.9 \pm 15.9$ & $16.7 \pm 19.3$ & 0.015 \\
\hline \multicolumn{4}{|c|}{$\begin{array}{l}\text { Data are presented as mean } \pm S D \text { except where indicated otherwise. }{ }^{*} A \text { pre- } \\
\text { scribing physician was any physician who prescribed asthma medication for a } \\
\text { member of the study group; }{ }^{\dagger} \text { For any asthma medication; }{ }^{\ddagger} \text { All physicians seen } \\
\text { by all patients in the study group, regardless of whether they prescribed } \\
\text { asthma medication. Reproduced with permission from reference } 10 . \\
\text { (c) Canadian Medical Association. }\end{array}$} \\
\hline
\end{tabular}

\section{Societal and economic impact}

From a societal perspective, exacerbations are the leading cause of asthma-related expenditures, accounting for almost $50 \%$ of the total costs associated with the disease (38). Patients who have frequent exacerbations (generally believed to be approximately $20 \%$ of the total asthma population pool) incur $80 \%$ of the total direct costs of asthma (39). The average annual cost per patient who experiences an exacerbation is estimated to be 3.5 times greater than those who do not experience exacerbations (40), and these costs appear to increase with increasing severity of the exacerbation (41). A retrospective chart review of 422 adults with asthma in Switzerland found direct costs to be 2.5 times higher in patients with the highest severity asthma compared with the lowest severity, if there were no exacerbations. If exacerbations were present, costs were 5.7 times greater (42). Therefore, strategies that can prevent asthma worsenings from developing into exacerbations may significantly lower the overall societal and economic costs of asthma. Furthermore, because the majority of asthma exacerbations ( $80 \%$ to $90 \%$ ) are slow-onset in nature, characterized by gradual clinical and functional worsening over a period of days or even weeks (26), strategies that can reduce the number of slow-onset exacerbations may also have a pronounced impact on costs.

Evidence suggests that asthma worsenings (as defined by increasing symptom severity or bothersomeness and increasing rescue medication use) may also have a direct impact on the economic and societal costs of asthma. Using computerized family practice database information as well as patient survey results, Van Ganse et al (9) found that low levels of asthma control (as measured by recent symptoms and increased SABA use) were a major correlate of total medical resource

\section{TABLE 6}

Proportion of patients reporting that worsening asthma limited/prevented their daily activities

\begin{tabular}{lc}
\hline Activity & Percentage of patients \\
\hline Exercise and physical activity & $73(n=2476)$ \\
Leisure activities & $49(n=1671)$ \\
Social commitments & $39(n=1340)$ \\
Intimacy with partner & $29(n=999)$ \\
Work & $28(n=973)$ \\
Time spent with family & $16(n=535)$ \\
\hline
\end{tabular}

Reproduced with permission from reference 4. (c) BioMed Central Ltd

utilization, including drug therapy, ambulatory care and hospital care. Compared with well-controlled asthma, poorly controlled asthma resulted in a significant 2.5 -fold increase in medical resource utilization costs. Interestingly, even the presence of asthma symptoms, such as wheezing in the past 12 months, was associated with increased medical resource utilization (9).

Another retrospective analysis of administrative data examined the pattern of health services utilization among asthmatic patients in British Columbia taking various SABA and ICS doses (10). Included in this analysis were all patients between five and 50 years of age for whom a prescription for a SABA was filled in 1995 and whose prescription data were captured through the provincial drug plan $(n=23,986)$. Inappropriate medication use was defined as the use of nine or more canisters of salbutamol (200 puffs, $100 \mu \mathrm{g} / \mathrm{puff}$, or an equivalent) combined with no more than $100 \mu \mathrm{g} /$ day of inhaled beclomethasone-CFC (or an equivalent) in a one-year period. Appropriate medication use was defined as four or fewer canisters of salbutamol and at least $400 \mu \mathrm{g} / \mathrm{day}$ of beclomethasone. Patients with inappropriate SABA and ICS use were more likely to be admitted to hospital (adjusted RR 1.68, 95\% CI 1.25 to 2.26), were admitted to hospital more frequently (adjusted RR 1.81, 95\% CI 1.41 to 2.32 ) and were more likely to require emergency admission (adjusted RR 1.93, 95\% CI 1.35 to 2.77) (Table 5) (10).

A drug utilization study based on an administrative data set of more than 20,000 asthmatic patients examined health care costs in those using high doses of SABAs (defined as greater than eight puffs per day). The results showed that annual treatment-related charges were 3.0 times higher in high SABA users than average asthmatic patients $(\$ 1,347$ versus $\$ 447$, respectively) (11). Therefore, regardless of whether asthma worsenings develop into exacerbations, episodes of increased asthma symptoms and high reliever use appear to be associated with increased personal, societal and economic costs.

\section{Impact on QOL}

Asthma worsenings also appear to negatively impact heathrelated QOL (HR-QOL). In the INSPIRE study (4), asthma worsenings were found to affect all aspects of patients' daily lives, particularly their physical and leisure activities, and social commitments (Table 6). Over $70 \%$ of patients stated that the worst drawbacks of having asthma were the interference in their daily lives and the panic they felt as their symptoms increased (4).

A study conducted in the Netherlands (43) examined the impact of symptoms on the HR-QOL of adolescents with asthma and found that patients experiencing episodes of wheezing had significantly lower QOL scores on nine of 


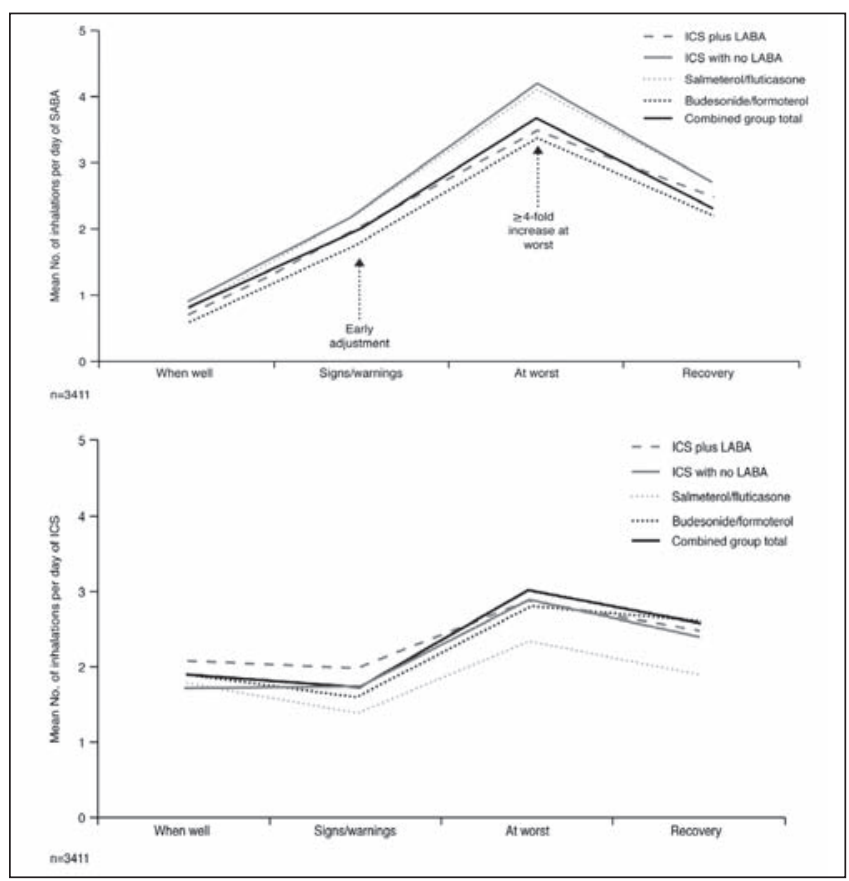

Figure 7) Use of short-acting beta-2 agonist (SABA) rescue medication and inhaled corticosteroid (ICS) maintenance medication during the different stages of an asthma worsening. All patients used ICS plus a separate long-acting beta-2 agonist (LABA) $(n=319)$, ICS alone $(n=1018)$, or a combination ICS/LABA product ( $n=2074$ : salmeterol/fluticasone, $n=1305$; budesonide/formoterol, $n=769$ ) for regular maintenance therapy. Data are based on all patients who reported using each medication type at each particular stage. Reproduced with permission from reference 4. (C) BioMed Central Ltd

10 domains of the Child Health Questionnaire-Child Form (43). Except for the Role Physical and Family Activities domains, significant differences in QOL were observed for all domains among adolescents who reported at least four wheezing episodes during the past year; most affected were the Bodily Pain, General Health, Self-Esteem and Mental Health domains (43). Further evidence that asthma worsenings negatively impact HR-QOL comes from a retrospective analysis of 2386 asthmatic patients aged five years and older who had used a SABA in the period from 1996 through 2000 (44). Use of SABA medication was defined as inappropriate when a patient inhaled more than 225 defined daily doses of SABAs but less than 45.63 defined daily doses of corticosteroids per year. Compared with appropriate SABA users, inappropriate SABA users had lower perceptions of their overall health $(\mathrm{P}<0.05)$ and mental health $(\mathrm{P}<0.05)$. They were also at an increased risk of limitations in walking (RR $1.76,95 \% \mathrm{CI} 1.15$ to 2.71 ) and in cognitive function (RR 2.32, 95\% CI 1.37 to 3.93) (44).

Using various asthma QOL questionnaires, Lloyd et al (45) studied the effect of exacerbations on 112 patients with moderate to severe asthma. Scores on all QOL instruments were significantly worse for patients experiencing exacerbations $(\mathrm{P}<0.001)$ compared with those not experiencing exacerbations and, according to the investigators, the differences in QOL scores between the two groups were clinically meaningful. There was also evidence of a further HR-QOL decrement

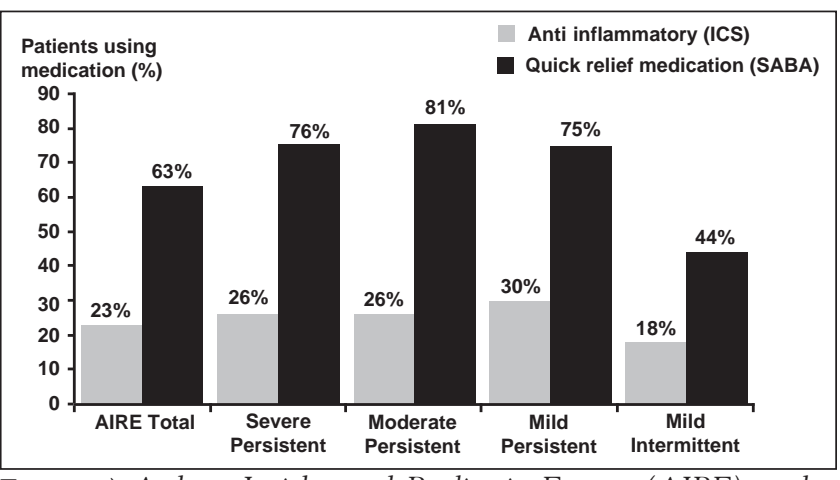

Figure 8) Asthma Insights and Reality in Europe (AIRE) study: short-acting beta-2 agonist (SABA) rescue medication and inhaled corticosteroid (ICS) use according to symptom severity. Adapted from reference 50

in those patients who had been admitted to hospital as a result of an exacerbation (45). Because exacerbations are a subset of asthma worsenings, these results suggest that some worsenings negatively impact patient QOL.

\section{Patient self-management of asthma worsenings}

The results of various studies suggest that the majority of patients adjust their medications inappropriately in response to asthma worsenings $(4,13,46-49)$. In the TRAC study (13), for example, more than $30 \%$ of patients using combination therapy and greater than $25 \%$ using an ICS never modified their medication regimen in response to an asthma worsening. Of those subjects that did modify their medication regimen, more than $60 \%$ took more SABA therapy than usual, less than $25 \%$ increased their ICS therapy and less than 10\% increased their combination ICS/LABA treatment. Patients with controlled and uncontrolled asthma adjusted their medications similarly to cope with asthma worsenings (13).

In the INSPIRE study (4), patients responded to the signs of an asthma worsening by increasing their medication; however, patients reported increasing their SABA use at the very onset of symptoms, with the ICS being increased later (and to a lesser extent), closer to the point of symptoms being at their worst (Figure 7). A greater than fourfold increase in the number of SABA inhalations was reported when symptoms were at their peak compared with when patients were well. When symptoms started to decrease, patients reduced their intake of both SABA and ICS therapy (4). Therefore, during an asthma worsening, ICS use is delayed and the duration of use is likely too short to experience benefit.

The Asthma Insights and Reality in Europe (AIRE) study (50) did not specifically examine asthma worsenings, but this comprehensive multinational survey of over 2000 asthma patients noted that greater than $45 \%$ of patients reported daytime symptoms and 30\% reported asthma-related sleep disturbances at least once per week. Furthermore, episodes of cough, wheezing, chest tightness and shortness of breath were common, occurring in $57 \%$ of adults at least once per month. Regardless of disease severity, there was a disturbingly high level of rescue medication use and low level of ICS use (Figure 8) (50), suggesting that asthma may be significantly undertreated and poorly controlled, regardless of whether patients experience transient asthma worsenings. 
Therefore, current evidence suggests that patients fail to respond in a timely manner and fail to respond appropriately to an asthma worsening by overusing rescue therapy and by underusing maintenance anti-inflammatory medication. Factors that may explain this suboptimal self-management of asthma worsenings are described in the following section.

\section{POTENTIAL BARRIERS TO APPROPRIATE SELF- MANAGEMENT OF ASTHMA WORSENINGS}

Factors that may explain patient failure to respond or to selfmanage appropriately during periods of asthma worsenings include failure to adequately identify periods of worsenings (4), low expectations for asthma control $(51,52)$, patient perceptions of and preferences for disease management $(53,54)$, low health literacy (55) and poor patient-health care professional communication regarding asthma worsenings (56).

In the INSPIRE study (4), approximately one-third of patients failed to identify signs of impending worsenings. Furthermore, patients tend to underestimate the level of severity of their asthma (57) and overestimate their level of asthma control $(3,13,58)$. Over $50 \%$ of patients in the TRAC study (13) were found to have uncontrolled asthma according to the Canadian Asthma Consensus Guidelines' control criteria $(1,59,60)$; however, only $3 \%$ of patients thought they had uncontrolled asthma (13). The INSPIRE study (4) also found a discrepancy between the level of asthma control demonstrated by the Asthma Control Questionnaire and patients' perceived level of control, suggesting that even patients prescribed maintenance medication and with recent physician contact tend to underestimate their asthma symptoms and tolerate suboptimal control. In the AIRE study (50), patient perception of asthma control did not match their symptom severity: approximately $50 \%$ of patients reporting severe persistent symptoms considered their asthma to be completely or well controlled. Together, these findings suggest that patients underestimate or tolerate asthma symptoms and, therefore, may fail to accurately identify periods of asthma worsenings and intervene appropriately.

Current literature also suggests that most patients have low expectations of what can be achieved by asthma management and, therefore, may believe that periods of asthma worsenings cannot be improved and are part of living with asthma. In the Living and Breathing Study (51), 517 patients receiving treatment for mild to moderate asthma participated in face-to-face interviews with market researchers. Approximately $90 \%$ of respondents felt their asthma was under control, yet two-thirds experienced symptoms at least two to three times per week. Only $24 \%$ felt their asthma could improve over time, and $71 \%$ received no advice from health care professionals on how their asthma might change in the future (51). According to Aboussafy et al (52), many patients with asthma who have poor symptom control make compromises in their lifestyle to adjust to life with asthma rather than striving to eliminate symptoms. Therefore, patients may believe asthma worsenings are part of the natural course of the disease and, hence, needlessly tolerate these episodes, using a 'wait and see' approach.

Self-management of asthma worsenings is also strongly influenced by patients' common-sense beliefs about the disease and medications. Patient adherence to medication is particularly influenced by the way in which patients evaluate their personal need for medication relative to their concerns about daily ICS use (53). Patients are more likely to doubt the necessity of treatment if they do not perceive a good fit with their common-sense understanding of their illness and symptom experiences relative to their expectations of medication effectiveness and asthma control. A prospective, 12-month, longitudinal, observational cohort study of 198 adults hospitalized with asthma found that one-half of these patients believed they only had asthma when they were having symptoms, what the investigators called the 'no symptoms, no asthma' belief (54). Individuals who had this belief of asthma as an acute, episodic condition were more likely to believe they would not always have asthma and that they would likely be cured; these patients were also less likely to think their lungs were always inflamed and needed maintenance therapy. Patients with this disease belief had lower rates of self-reported adherence to ICS therapy and a lower likelihood of participating in other key selfmanagement tasks such as routinely visiting their physician for asthma or monitoring their peak flow (54).

Both patients' concerns about and preferences for asthma medication may also be important factors impacting the selfmanagement of asthma worsenings. In the TRAC study (13), patients revealed significant fears about medications. Approximately $75 \%$ of patients were concerned about side effects and almost $90 \%$ wanted to use lower doses of medications in general. Approximately three-quarters of patients expressed concerns about using ICS therapy and $81 \%$ hoped to decrease their use. A discrete choice experiment conducted in adults with moderate to severe asthma found that patients wanted no more than one or two inhalers and that they wanted the lowest dose of ICS possible and were willing to trade off or accept occasional symptoms to take fewer doses (61). Participants also identified a simple treatment regimen as most important, even more important than symptom control.

Patient health literacy is another factor that may negatively impact self-management of asthma and asthma worsenings. A cross-sectional study of 395 English-speaking adults waiting to see their health care providers showed that lower literacy and a greater number of prescription medications were independently associated with misunderstanding the instructions on prescription medication labels (55). Approximately one-half $(46.3 \%)$ of these patients were unable to read and correctly state one or more of the label instructions on five common prescriptions. Rates of misunderstanding were highest among patients with marginal and low literacy (as measured by the Rapid Estimate of Adult Literacy in Medicine - a reading recognition test comprising 66 health-related words), yet more than one-third (37.7\%) of patients with adequate literacy skills misunderstood at least one of the label instructions. For example, among the patients correctly stating the instruction, "Take two tablets by mouth twice daily" ( $\mathrm{n}=333$ [84.3\%]), onethird were unable to demonstrate the correct number of pills to take per day. This was most pronounced among patients with low literacy; fewer than one-half who correctly stated the instruction were then able to count the correct number of pills (55).

Finally, failure to develop a common language or understanding of asthma worsenings among patients and health care providers is also likely to be a significant barrier to appropriate self-management of these episodes. A qualitative 
study examining the terms or phrases patients use to describe asthma worsenings found no universally accepted terms or phrases for describing such episodes (56). Some of the descriptors used by patients include 'attacks', 'flare-ups' or 'asthma acting up'. The term 'exacerbation' was not regarded by patients as being useful for communicating about an asthma worsening. Without readily understood and unambiguous words for use in educational materials and asthma action plans, communication breakdown may occur (56), impeding appropriate and timely management of an asthma worsening.

\section{EVIDENCE-BASED APPROACHES TO THE PREVENTION AND MANAGEMENT OF ASTHMA WORSENINGS}

Given the prevalence of asthma worsenings, their relationship to exacerbations, the impact on QOL, and potential societal and economic consequences, strategies for the early identification, prevention and management of worsenings are clearly imperative. This section highlights possible pharmacological and nonpharmacological approaches to the prevention and management of asthma worsenings based on current literature.

\section{Pharmacological approaches}

Although there are currently no randomized trials specifically addressing therapeutic interventions for asthma worsenings as a primary outcome, numerous studies have examined strategies for the prevention of exacerbations that, as discussed previously, are a subset of asthma worsenings. It can therefore be theorized that any intervention that prevents exacerbations may also prevent asthma worsenings. Furthermore, because the definition of mild exacerbation days used in various clinical trials of pharmacological interventions is similar to the AWWG definition of asthma worsenings, the impact of these interventions on mild exacerbation days are considered because they are also likely to affect asthma worsenings.

Various randomized controlled trials have confirmed that ICS therapy, with or without LABA therapy, reduces the risk of both severe and mild exacerbations (14,21,33,34,62-64). In the past, most asthma guidelines recommended a doubling of the dose of maintenance ICS therapy early in a mild asthma exacerbation. However, recent randomized controlled trials have shown no differences in the prevention of more severe exacerbations between patients who continued on their maintenance ICS dose and those in whom the ICS dose was doubled $(65,66)$.

Recent evidence also suggests that early intervention with combination ICS/LABA therapy may the optimal strategy for the prevention of both asthma worsenings and exacerbations $(8,14,21-23,64)$. In a double-blind, parallel group study, Lundbäck et al (21) randomly assigned 282 symptomatic asthma patients (18 to 70 years of age) to receive either salmeterol, fluticasone or combination salmeterol/fluticasone twice daily for 12 months. Primary outcome variables included the number of patients requiring an increase in study medication and the number of patients experiencing two or more exacerbations. Significantly fewer patients experienced two or more exacerbations with combination salmeterol/fluticasone $(4.2 \%)$, compared with fluticasone $(17.4 \% ; \mathrm{P}<0.01)$ or salmeterol (40\%; P<0.001) (21).

When considering days with symptoms (opposite of symptomfree days) as asthma worsenings, the study found higher

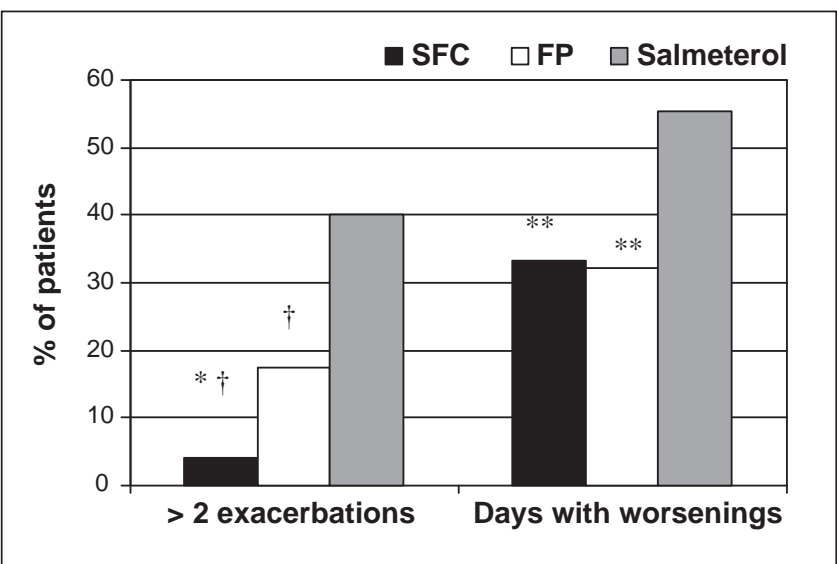

Figure 9) Percentage of patients with asthma worsenings (opposite of symptom-free days) and two or more exacerbations according to treatment group. Days with worsenings defined as opposite of symptom-free days. $* P<0.01$ for combination salmeterol/fluticasone (SFC) versus fluticasone propionate (FP); ${ }^{\dagger} \mathrm{P}<0.001$ for $F P$ versus salmeterol and $S F C$ versus salmeterol; $* * P<0.05$ for SFC versus salmeterol and FP versus salmeterol. Adapted from reference 21

proportions of asthma worsenings in patients treated with salmeterol than those treated with combination salmeterol/fluticasone or fluticasone alone $(\mathrm{P}<0.05$; Figure 9$)$. In addition, the median proportion of rescue medication-free days was significantly higher in the combination salmeterol/fluticasone $(85.7 \%)$ and fluticasone $(85.7 \%)$ groups than in the salmeterol group $(60 \%$; $\mathrm{P}<0.05$; Figure 9$)$. However, there were no significant differences between combination salmeterol/fluticasone or fluticasone alone with regard to days with symptoms or rescue-free days (21).

Although the international Gaining Optimal Asthma Control (GOAL) study (64) - a stratified, double-blind, parallel group study of 3421 patients (12 years to younger than 80 years of age) with uncontrolled asthma - did not examine mild exacerbations or asthma worsenings, this study did compare the efficacy of stepwise increases in fluticasone or combination salmeterol/fluticasone in achieving two predefined composite measures of asthma control: totally controlled or well-controlled asthma (Table 7) (64). Given the definition of totally controlled asthma as shown in Table 7, it can be theorized that patients achieving this level of control would experience no worsenings.

Significantly more patients in each stratum (previously corticosteroid-free, or previous low-dose or moderate-dose corticosteroid users) achieved control with combination salmeterol/fluticasone than fluticasone alone. After dose escalation, total control was achieved in $42 \%$ and $31 \%$ of patients for salmeterol/fluticasone and fluticasone, respectively, in the previously steroid-naïve stratum (OR $1.71 ; 95 \%$ CI 1.30 to 2.24; $\mathrm{P}<0.001$ ), $32 \%$ and $20 \%$ in the stratum previously on a lowdose ICS (OR 2.07; 95\% CI 1.56 to 2.76; P<0.001), and 19\% and $8 \%$ in the stratum previously on moderate-dose ICS (OR $2.90 ; 95 \%$ CI 1.98 to 4.26 ; $<<0.001)$. By the end of the oneyear study period, the results for totally controlled asthma in the salmeterol/fluticasone and fluticasone groups, respectively, were $50 \%$ and $40 \%$ in the previously steroid-naïve stratum, 


\section{TABLE 7}

Gaining Optimal Asthma Control (GOAL) study: Definitions of well-controlled and totally controlled asthma based on Global Initiative for Asthma (GINA) and National Institutes of Health (NIH) guideline aims of treatment

\begin{tabular}{|c|c|c|c|}
\hline & $\begin{array}{l}\text { Goals of GINA/ } \\
\text { NIH }\end{array}$ & $\begin{array}{l}\text { Totally } \\
\text { controlled: } \\
\text { each week all of }\end{array}$ & $\begin{array}{l}\text { Well controlled } \\
\text { each week } 2 \text { or } \\
\text { more of }\end{array}$ \\
\hline $\begin{array}{l}\text { Daytime } \\
\text { symptoms }\end{array}$ & $\begin{array}{l}\text { Minimal (ideally } \\
\text { none) }\end{array}$ & None & $\begin{array}{l}\leq 2 \text { days with } \\
\text { symptom score } \\
>1^{*}\end{array}$ \\
\hline $\begin{array}{l}\text { Rescue } \beta_{2-}^{-} \\
\text {agonist use }\end{array}$ & $\begin{array}{l}\text { Minimal (ideally } \\
\text { none) }\end{array}$ & None & $\begin{array}{l}\text { Use on } \leq 2 \text { days } \\
\text { and } \leq 4 \text { occas- } \\
\text { sions/wk }\end{array}$ \\
\hline Morning PEF & Near normal & $\begin{array}{l}\geq 80 \% \text { predicted }^{\dagger} \\
\text { every day }\end{array}$ & $\begin{array}{l}\geq 80 \% \text { predicted }^{\dagger} \\
\text { every day }\end{array}$ \\
\hline $\begin{array}{l}\text { Night-time } \\
\text { awakening }\end{array}$ & $\begin{array}{l}\text { Minimal (ideally } \\
\text { none) }\end{array}$ & None & None \\
\hline Exacerbations $^{\ddagger}$ & $\begin{array}{l}\text { Minimal } \\
\quad \text { (infrequent) }\end{array}$ & None & None \\
\hline Emergency visits & None & None & None \\
\hline $\begin{array}{l}\text { Treatment-related } \\
\text { adverse events }\end{array}$ & Minimal & $\begin{array}{l}\text { None enforcing } \\
\text { change in asthma } \\
\text { therapy }\end{array}$ & $\begin{array}{l}\text { None enforcing } \\
\text { change in asthma } \\
\text { therapy }\end{array}$ \\
\hline
\end{tabular}

Totally and well-controlled asthma were defined by achievement of all of the specified criteria for that week. Totally controlled asthma was achieved if the patient, during the eight consecutive assessment weeks, recorded seven totally controlled weeks and had no exacerbations, emergency room criteria or medication-related adverse events criteria. Well-controlled asthma was similarly assessed over the eight weeks. These assessments were for an eightweek period during the double-blind treatment period. Baseline control and control during the open-label phase were assessed over a four-week period. *Symptom score: 1 was defined as "symptoms for one short period during the day." Overall scale: 0 (none) to 5 (severe); ${ }^{\dagger}$ Predicted peak expiratory flow (PEF) was calculated based on the European Community for Steel and Coal standards for patients 18 years of age and older and on the Polgar standards for patients 12 to 17 years of age; ₹Exacerbations were defined as deterioration in asthma requiring treatment with an oral corticosteroid or an emergency department visit or hospitalization. Reproduced with permission from reference 64. @ American Thoracic Society

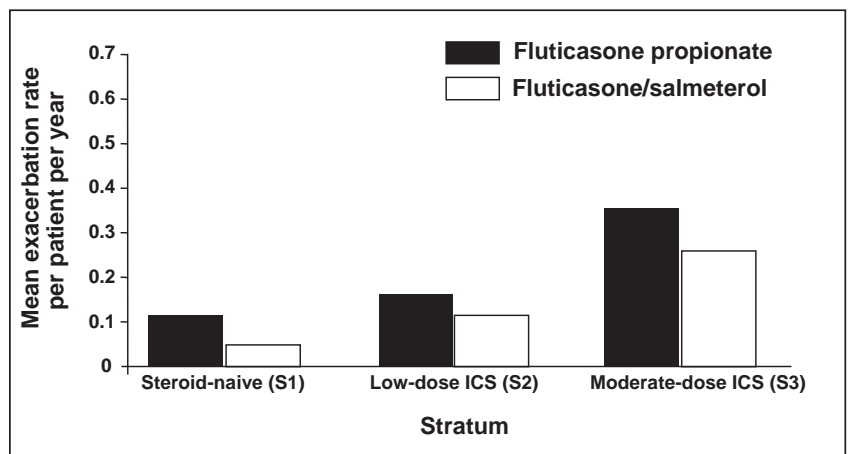

Figure 10) Gaining Optimal Asthma Control (GOAL) study: Mean rate of exacerbations requiring either oral steroids or hospitalization/emergency visits per patient per year over the one-year study period according to inhaled corticosteroid (ICS) use in the previous six months. $P \leq 0.009$ salmeterol/fluticasone versus fluticasone alone, all strata. Reproduced with permission from reference 64. (C) 2004 American Thoracic Society

$44 \%$ and $28 \%$ in the patients previously on low-dose ICS and $29 \%$ and $16 \%$ in the patients previously on moderate-dose ICS (all strata $\mathrm{P}<0.001$ ) (64).

The mean annual rates of exacerbations requiring oral corticosteroids and/or hospitalization or emergency visits were low

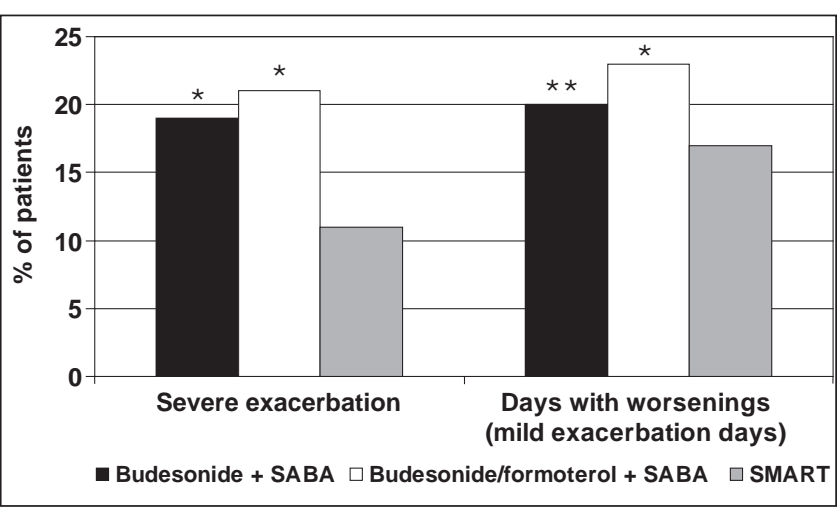

Figure 11) STAY study: Percentage of patients with severe exacerbations and days with asthma worsenings (mild exacerbation days) according to treatment group. ${ }^{*} \mathrm{P}<0.001$ for single-inhaler budesonide/formoterol maintenance and reliever therapy (SMART) versus budesonide + short-acting beta-2 agonist (SABA) and versus budesonide/formoterol + SABA for severe exacerbations; SMART versus budesonide/formoterol + SABA for days with worsenings; $* * P<0.03$ for SMART versus budesonide + SABA for days with worsenings. Adapted from reference 14

in both treatment groups, but were significantly lower in the salmeterol/fluticasone group in each stratum (Figure 10) (64).

More recent evidence suggests that single-inhaler budesonide/formoterol maintenance and reliever therapy (SMART) is also an effective strategy for the prevention of asthma worsenings and may be the optimal strategy for the prevention of exacerbations. In patients requiring maintenance and reliever therapy, the substitution of single-inhaler budesonide/formoterol for a SABA allows the dose of maintenance therapy to be increased quickly in response to symptoms, while simultaneously offering rapid intervention to decrease inflammation, whether eosinophilic or neutrophilic. In fact, this novel treatment approach has recently been recognized in the latest update to the Global Initiative for Asthma (GINA) guidelines (2).

The STAY study (14) was a randomized, double-blind, oneyear study that compared SMART to fixed-dose budesonide/ formoterol or a fourfold higher dose of budesonide alone, both with a SABA as reliever, in patients with moderate to severe asthma ( $n=2760$, aged four to 80 years). The primary outcome variable in the study was time to first severe asthma exacerbation, defined as deterioration in asthma resulting in hospitalization/emergency department treatment, oral steroid treatment, or morning PEF $70 \%$ or lower of baseline on two consecutive days (14). Results of the study demonstrated that SMART significantly prolonged the time to the first severe exacerbation compared with both fixed-dose budesonide/formoterol plus SABA and higher-dose budesonide plus SABA. The risk of experiencing a severe asthma exacerbation with SMART was $45 \%$ lower than in the budesonide/formoterol plus SABA group and $47 \%$ lower than the group receiving a fourfold higher dose of budesonide plus as-needed SABA (Figure 11). This magnitude in the reduction of severe exacerbations was consistent in children, adolescents and adults (14).

The STAY study (14) also assessed the number of patients with mild exacerbation days (asthma worsenings), which were 
defined as any day with an awakening caused by asthma, with as-needed medication use of two or more inhalations above the baseline mean value or with a morning PEF of $80 \%$ or less of the baseline mean value. The percentage of days with asthma worsenings were significantly lower in patients using SMART than in those using combination budesonide/formoterol plus SABA and those using higher dose budesonide alone plus SABA (Figure 11). The rate of worsenings (mild exacerbation days/subject) was 30\% lower for SMART compared with combination budesonide/formoterol plus SABA (hazard ratio [HR] 0.70; 95\% CI 0.62 to 0.80) and $36 \%$ lower compared with budesonide (HR 0.64; 95\% CI 0.57 to 0.73 ). The SMART regimen was also associated with less reliever medication use and night-time symptoms including awakenings and improved lung function compared to the other treatment groups (14).

The SMILE study (22) was a 12-month, randomized, double-blind, parallel group trial of 3394 patients with asthma (12 years of age and older) using budesonide/formoterol maintenance therapy. SMILE was designed to evaluate the additional benefits of the following as-needed therapies in preventing asthma exacerbations: budesonide/formoterol, formoterol or terbutaline. The results of the study showed that time to first severe exacerbation was significantly longer with as-needed budesonide/formoterol compared with formoterol $(\mathrm{P}=0.0048$; log-rank-test $)$ and terbutaline $(\mathrm{P}<0.0001)$, and with as-needed formoterol compared with terbutaline $(\mathrm{P}=0.0051)$. As-needed budesonide/formoterol reduced the instantaneous risk of a severe exacerbation by $27 \%$ (HR 0.73 , $95 \% \mathrm{CI} 0.59$ to $0.90 ; \mathrm{P}=0.0038$ ) versus formoterol and by $45 \%$ (HR $0.55,95 \%$ CI 0.45 to 0.68 ) versus terbutaline (22).

Significant improvements were also noted in asthma worsenings (mild exacerbation days), which were defined as any night with an awakening due to asthma, morning PEF of $20 \%$ or more below baseline morning PEF, or as-needed medication use of two or more inhalations in $24 \mathrm{~h}$ above baseline. Days with worsenings (mild exacerbation days) were reduced by $10 \%$ to $18 \%$ with as-needed budesonide/formoterol compared with either as-needed formoterol $(\mathrm{P}=0.043)$ or terbutaline $(\mathrm{P}<0.0001)$. The rate of mild exacerbations (defined as two mild exacerbation days as described above) was also significantly lower for patients using as-needed budesonide/ formoterol (Figure 12) (22). These findings suggest that the benefit achieved by using budesonide/formoterol as reliever, in addition to its use as maintenance therapy, is due to the rescue use of both the ICS and LABA components.

The COMPASS trial (23) - a double-blind, six-month study of 3335 symptomatic adults and adolescents - compared SMART with fixed-dose salmeterol/fluticasone and fixed-dose budesonide/formoterol both with as-needed SABA. The study found that SMART significantly prolonged the time to first severe exacerbation (defined as deterioration in asthma requiring hospitalization, ER treatment or oral steroids) compared with the other treatment groups (log-rank test $\mathrm{P}=0.0034$ versus fixed-dose salmeterol/fluticasone, and $\mathrm{P}=0.023$ versus fixeddose budesonide/formoterol). There was a $33 \%$ reduction in the HR for a first severe exacerbation with SMART compared with salmeterol/fluticasone (HR 0.67; 95\% CI 0.52 to 0.87 ; $\mathrm{P}=0.003)$ and a $26 \%$ reduction compared with fixed-dose budesonide/formoterol (HR 0.74; 95\% CI 0.56 to 0.96 ;

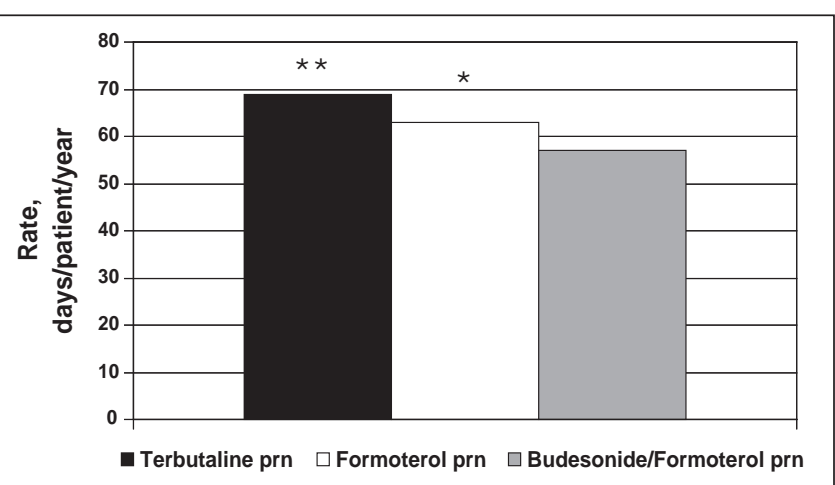

Figure 12) SMILE study: Number of mild exacerbations per patient per year according to treatment group. ${ }^{*} P=0.043$ for as-needed (prn) budesonide/formoterol versus prn formoterol; **P=0.0001 for prn budesonide/formoterol versus prn terbutaline. Adapted from reference 22

$\mathrm{P}=0.026)$. However, no significant differences were seen between the SMART group and the two fixed-dose regimens in terms of the number of mild exacerbation days (defined as a day with morning PEF $20 \%$ or more below baseline, daily asneeded medication use two or more inhalations above baseline or a night with an asthma-related awakening) or the time to a mild exacerbation (defined as two consecutive mild exacerbation days as described above) (23).

In the AHEAD trial, Bousquet et al (8) randomly assigned 2309 patients with symptomatic asthma (aged 12 years and older; FEV 1 50\% predicted or greater) who had experienced an asthma exacerbation in the previous year to receive SMART (budesonide/formoterol 160/4.5 $\mu$ g two inhalations twice daily and as needed) or one inhalation of salmeterol/fluticasone 50/500 $\mu$ g twice daily plus as-needed SABA for six months. Time to first severe exacerbation, the prespecified primary outcome, was not significantly prolonged with the SMART approach, and differences in measures of lung function or asthma symptoms were not observed between the two treatment groups. However, the SMART approach was associated with a $21 \%$ reduction in overall exacerbation rate (25 events/100 patients/year versus 31 events/100 patients/year; $\mathrm{P}=0.039)$ and a $31 \%$ reduction in the rate of hospitalization/ER treatment ( 9 events/100 patients/year versus 13 events/100 patients/year; $\mathrm{P}=0.046)$ compared with high-dose salmeterol/ fluticasone (8).

There are observations to suggest that SMART may be more effective than fixed-dose combination ICS/LABA therapy plus as-needed SABA during periods of asthma worsenings. In the AHEAD trial (8), days with an increased number of as-needed inhalations (more than two, four, six and eight inhalations/day) were used to identify periods of asthma worsenings. The pattern of severe exacerbations following these high rescue-use days revealed that SMART provided patients with greater protection from severe exacerbations at times of asthma worsenings (Figure 13). The percentage of subjects with one or more exacerbations increased more strikingly with the level of as-needed use in the high-dose salmeterol/fluticasone plus SABA group than with the SMART approach (8). 


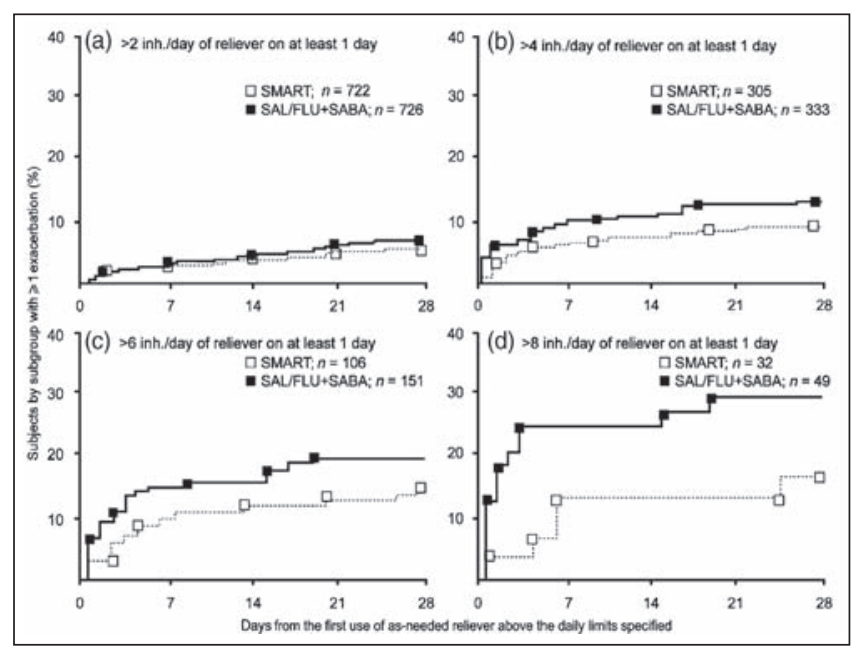

Figure 13) AHEAD study: Kaplan-Meier plots showing the percentage of patients experiencing $\geq 1$ exacerbation in the month following the first day with $>2$ (a), $>4$ (b), >6 (c) and >8 (d) inhalations/day of as-needed medication. inh Inhalations; SAL/ FLU + SABA Salmeterol/fluticasone + short-acting beta-2 agonist; SMART Budesonide/formoterol maintenance and reliever therapy. Reproduced with permission from reference 8 (erratum). (C) Elsevier

\section{Cost-effectiveness of the SMART strategy}

In addition to being effective in preventing asthma worsenings and severe exacerbations, the SMART strategy may also be more cost-effective than physician-directed titration of combination ICS/LABA therapy $(67,68)$. Using data from a 12-month, open-label study $(n=2143)$, Miller et al (67) performed a Canadian economic analysis to compare the costs of SMART versus salmeterol/fluticasone plus as-needed SABA from both a health care and societal perspective. For the health care perspective, costs associated with physician visits, other health care professional services, hospitalizations, ER visits, home care and medications were considered. The societal perspective included both the costs from the health care perspective as well as the cost of time lost from work. The SMART approach was associated with a relative cost savings of $\$ 226$ per patient per year from a health care perspective and $\$ 316$ per patient per year from a societal perspective (Figure 14) compared with the salmeterol/fluticasone plus as-needed SABA approach, and these results were stable under sensitivity testing (67). Another cost-effectiveness analysis from the United Kingdom found total cost savings of $£ 87 /$ patient/six months and $£ 91 /$ patient/6 months compared with salmeterol/fluticasone and fixed-dose budesonide/formoterol, respectively (68). This translates into a relative cost savings of approximately $\$ 340$ to $\$ 360$ per patient per year with the SMART approach.

\section{Potential concerns related to the SMART strategy}

A major concern raised about SMART is that patients may overuse the budesonide/formoterol reliever and needlessly receive high ICS doses. However, the STAY study found that the benefits achieved with SMART occurred with a mean daily dose of budesonide of $240 \mu \mathrm{g} /$ day in adults and $126 \mu \mathrm{g} /$ day in children, compared with a maintenance dose of budesonide of

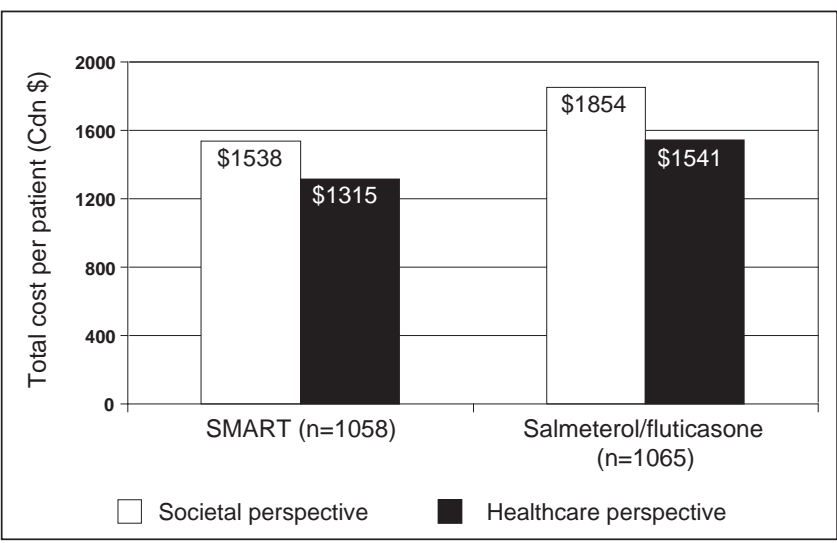

Figure 14) Total societal and health care costs per patient per year according to treatment group. SMART Single inhaler budesonidel formoterol maintenance and reliever therapy. Adapted from reference 67

$640 \mu \mathrm{g} /$ day in adults and $320 \mu \mathrm{g} /$ day in children $(14,69)$. The COMPASS trial (23) found an overall reduction in mean ICS dose in the SMART group $(483 \mu \mathrm{g} /$ day or $755 \mu \mathrm{g} /$ day beclomethasone dipropionate [BDP] equivalent) compared with both fixed dose groups $(640 \mu \mathrm{g} /$ day [1000 $\mu \mathrm{g} /$ day BDP equivalent] for budesonide/formoterol and $500 \mu \mathrm{g} /$ day [1000 $\mu \mathrm{g} /$ day BDP equivalent] for salmeterol/fluticasone). The AHEAD trial (8) also found that the mean ICS dose was lower using SMART (792 $\mu \mathrm{g} /$ day budesonide [1238 $\mu \mathrm{g} /$ day BDP equivalent] versus $1000 \mu \mathrm{g} /$ day fluticasone [2000 $\mu \mathrm{g} /$ day BDP equivalent] with salmeterol/fluticasone therapy; $\mathrm{P}<0.0001$ ). These findings suggest that it is the timely increase in anti-inflammatory therapy resulting from the as-needed use of budesonide/formoterol for symptom relief rather than the total inhaled dose of ICS that explains the noted benefits of SMART compared with fixeddose ICS/LABA regimens plus SABA for relief (8).

A further concern has been that patients might assume an as-needed approach to their overall asthma management strategy, but it should be emphasized that the baseline treatment in the SMART strategy is a maintenance dose of at least one inhalation twice daily of the combination inhaler. This strategy alone will be effective in achieving asthma control for many patients.

\section{Potential benefits of the strategy}

A very practical consideration with the SMART strategy is that a patient may control his or her asthma with just a single inhaler, providing both maintenance treatment as well as reliever therapy. Therefore, the SMART approach may improve patient adherence to therapy or compensate for poor adherence with regular anti-inflammatory maintenance therapy $(4,13,50)$. Typically, patients take their rapidly acting reliever to obtain symptom relief. With the SMART approach, they are also receiving an increased ICS dose, likely at a time when inflammation is worsening. This may explain why singleinhaler maintenance plus reliever therapy is effective against exacerbations.

In a recent review, Barnes (29) explains the mechanisms by which SMART may prevent exacerbations, and possibly asthma worsenings. Although formoterol provides effective symptom relief through relaxation of airway smooth muscle, it 
also has important inhibitory effects on mast cells, plasma exudation and neutrophilic inflammation. ICS therapy appears to have a much more rapid suppressing effect on airway inflammation than previously recognized and, therefore, the increased dose of budesonide received when used as rescue therapy may prevent the increase in airway inflammation that occurs during the evolution of an exacerbation, thus preventing its development. Barnes also suggests that the molecular interactions between the LABA and ICS may enhance the effect of the combination as rescue therapy (29). Although not yet studied clinically, these findings likely relate to other ICS/LABA combinations such as salmeterol/fluticasone.

\section{Nonpharmacological interventions}

The first steps in the prevention and management of asthma worsenings are understanding the disease trajectory, anticipating asthma worsenings resultant from trigger exposure, and early identification and action at the first signs of symptom worsening. Physicians and other health care professionals involved in asthma care need to regularly follow-up with and ask patients about the frequency and bothersomeness of asthma symptoms and awakenings, and the frequency of both rescue and maintenance therapy use. Because the majority of asthma visits are brief consultations in the primary care setting, a simple and quick tool for the assessment of worsenings is imperative (70). According to a study by McCoy et al (16), the AS-2 may be helpful in identifying patients with asthma worsenings. In this study, increasing levels of symptoms as revealed by the AS-2 were strongly associated with the probability of a subsequent worsening or exacerbation. The AS-2 is a simple test that has been suggested to be more relevant to clinical practice than other questionnaires assessing asthma symptoms. The AS-2 score is the average of the numeric responses to the following four questions:

1. How many days were you bothered by coughing during the past 2 weeks?

2. How many days were you bothered by wheezing during the past 2 weeks?

3. How many days were you bothered by shortness of breath during the past 2 weeks?

4. How many days were you awakened at night by your asthma during the past 2 weeks?

Each question has the following possible responses: 1 (not at all), 2 (1-3 days), 3 (4-7 days) and 4 (8-14 days). These questions represent a subset of the questions used for the Asthma Symptom Utility Index, which has been found to be reproducible (intraclass correlation coefficient $=0.74$ ) and significantly correlated with $\mathrm{FEV}_{1} \%$ predicted $(\mathrm{r}=0.27, \mathrm{P}<0.001)$, the Asthma Quality of Life Questionnaire $(r=0.77, P<0.001)$, and the Health Utilities Index Mark 2 ( $r=0.36, P<0.001)(71)$. There are even simpler validated tools for assessing asthma control over the previous week, a period of time relevant to detecting an asthma worsening in time to prevent an exacerbation $(72,73)$. These and other measures of control appear able to detect both 'good' and 'poor' control, but may be insensitive to the needs of patients experiencing asthma worsenings who may not fit within these control definitions $(74,75)$.

Patient self-management plans have also been shown to reduce the frequency and severity of exacerbations (76-81) and improve asthma-related QOL (82) and, therefore, such plans will be critical to the optimal prevention and management of asthma worsenings. A systematic review (78) of 36 randomized controlled trials involving 6090 participants who received asthma self-management education, an asthma action plan and regular practitioner review observed a reduction in the proportion of subjects with an exacerbation requiring admission to hospital, an ER visit for asthma or an unscheduled physician visit. A similar systematic review of studies involving children and adolescents also found that educational interventions for asthma self-management improved lung function and feelings of self control, and reduced absenteeism from school, number of days with restricted activity, number of ER visits, as well as the frequency of night-time symptoms (83). In fact, evidence suggests that both patients and physicians desire further asthma education. In the TRAC study (13), 98\% of physicians and more than $90 \%$ of patients $(93 \%$ with uncontrolled disease versus $95 \%$ with controlled disease) agreed that more asthmarelated patient education was needed.

Therefore, self-management education and asthma action plans that support patients in identifying signs of worsenings and that explain how to intervene immediately during these episodes will be central to the prevention and optimal management of asthma worsenings. Two studies $(84,85)$ that instructed patients to increase their ICS/LABA maintenance dose during periods of worsenings demonstrated improved asthma control compared with regimens involving fixed-dose combination therapies plus as-needed reliever medication.

Health care professionals must collaborate with the patient to design a flexible, acceptable, individualized self-management plan that not only addresses the prevention and management of worsenings, but that also takes into account patient goals and aspirations. Explicitly eliciting patient goals (ultimate outcomes or results) for successful asthma management and using these as a basis for treatment and management recommendations may allow professionals to identify more effectively motivators that activate patients to be more engaged in the day-to-day management of their asthma and facilitate an awareness and assessment of meaningful changes in their asthma control that will serve to reinforce positive management approaches.

It is important that health care professionals also identify the reasons for asthma worsenings and explore patients' common-sense beliefs about these episodes (70). In other words, what is their everyday understanding of their asthma and how do they make sense of it? Health care professionals can provide information about asthma and medications; however, unless the information addresses patients' common-sense beliefs about asthma and its treatment and management, it will not change behaviour. The ability to identify and address misplaced health beliefs (eg, "I only have asthma when I have symptoms") can be improved by tailoring education to the patient's understanding and management of asthma, learning style, readiness to learn, literacy level, and personal needs and goals. A simple and convenient treatment regimen that can be tailored to these patient characteristics is important. None of this can occur without establishing a patient-health care professional relationship characterized by effective communication. It is important that health care professionals use the language of the patient to improve understanding of the 


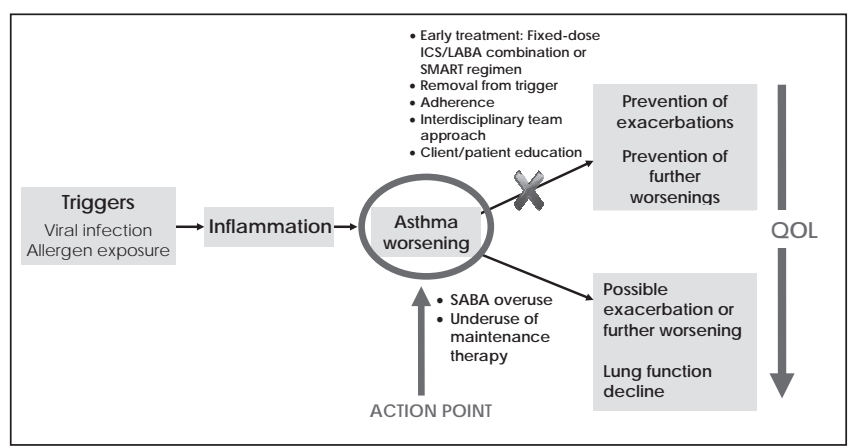

Figure 15) Asthma worsenings: Overview. ICS Inhaled corticosteroid; LABA Long-acting beta-2 agonist; QOL Quality of life; SABA Short-acting beta-2 agonist

patient's perspective and mutual goal setting. Research reveals that the descriptor often used by patients to describe asthma worsenings is breathlessness (4), suggesting that the language of breathlessness be used during encounters with asthma patients.

Finally, an interdisciplinary team approach involving primary care practitioners, pharmacists, certified asthma educators and specialists is likely to have the greatest impact on the prevention, identification and management of asthma worsenings. A demonstration project conducted with seven community clinics treating approximately 3000 children with asthma (aged five to 18 years) found that an interdisciplinary team approach based on a shared decision-making model that involved practice data feedback, a clinician champion and continuous quality improvement processes reduced the proportion of frequent SABA users from $42 \%$ to less than $12 \%$ (86). As previously discussed, frequent SABA use is a surrogate marker for asthma worsenings.

Evidence also suggests that pharmacists working in the community setting are ideally suited to identify patients with asthma worsenings, as defined by SABA overuse, and have the potential to make a significant impact on clinical outcomes in these patients. The majority of community-based studies focusing on pharmacist interventions for asthma have shown positive clinical outcomes in patients participating in these interventions compared with study controls (87). A six-month, randomized, controlled, parallel-group trial conducted in 66 community pharmacies in Belgium found that Asthma Control Test scores significantly increased in adult patients with uncontrolled asthma who received a predefined pharmacist intervention aimed at ensuring optimal use of asthma medication $(n=107)$ compared with those who received usual pharmacist care $(n=94)(88)$. It should be noted that patients with seriously uncontrolled asthma were referred to their physician.

The intervention significantly reduced reliever medication use (mean reliever use of 0.9 puffs/day versus 0.67 puffs/day in the control and intervention groups, respectively, at six months; $\mathrm{P}=0.01$ ) and the frequency of night-time awakenings due to asthma (mean of 10.7 awakenings versus 3.9 awakenings in the control and intervention groups, respectively, in a 14-day period; $\mathrm{P}=0.04$ ). The intervention also improved medication adherence (mean adherence rate as judged by

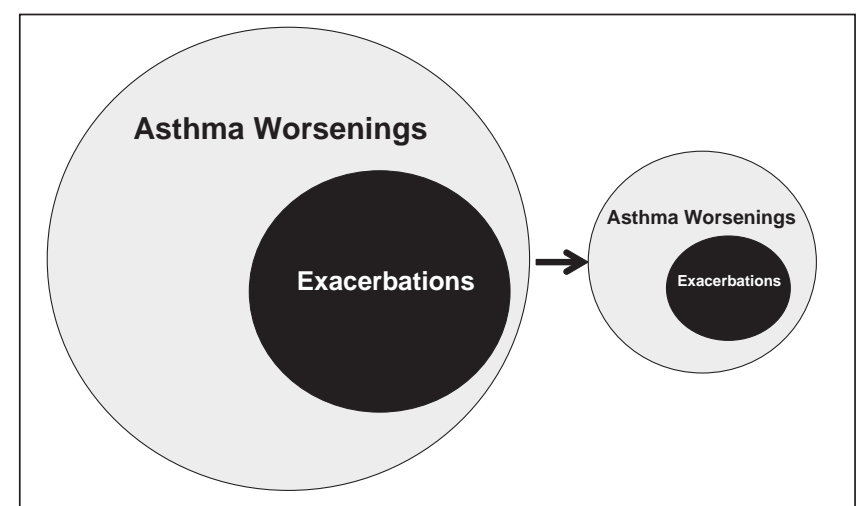

Figure 16) Theoretical impact of early treatment with single-inhaler budesonide/formoterol maintenance and reliever therapy (SMART) or fixed-dose inhaled corticosteroids/long-acting beta-2 agonist combination therapy on the occurrence of exacerbations or further asthma worsenings

prescription refills was $74.6 \%$ versus $90.3 \%$ for the control and intervention groups, respectively; $\mathrm{P}=0.02$ ) and inhalation technique (percentage of patients performing inhalation maneuvers correctly was $36.5 \%$ and $64.3 \%$ in the control and intervention groups, respectively; $\mathrm{P}=0.004$ ) (88).

Another six-month, randomized study (89) of 50 Australian pharmacies and 396 adult asthmatic patients found that a pharmacist-delivered asthma care program based on ongoing assessment, goal setting, monitoring and review improved asthma control compared with usual pharmacist care. Patients participating in the pharmacy asthma care program were 2.7 times more likely to improve from 'severe' to 'not severe' than control patients (OR 2.68, 95\% CI 1.64 to 4.37; $\mathrm{P}<0.001$ ). Participation in the program also improved adherence to preventer medication (OR $1.89,95 \%$ CI 1.08 to 3.30; $\mathrm{P}=0.03$ ), decreased the mean daily dose of reliever medication (difference $-149.1 \mu g, 95 \% \mathrm{CI}-283.87$ to $-14.36 ; \mathrm{P}=0.03$ ), and resulted in a shift in medication profile from reliever only to a combination of preventer plus reliever with or without a LABA (OR 3.80, 95\% CI 1.40 to 10.32 ; $\mathrm{P}=0.01$ ) (89).

These results suggest that a community pharmacist intervention, targeting overusers of SABA therapy and underusers of maintenance therapy, may also help prevent asthma worsenings.

\section{SUMMARY}

Asthma worsenings represent an exciting new concept in asthma management that provides patients, physicians and other health care professionals with a novel window of opportunity for early intervention and the prevention of exacerbations or further deterioration of asthma symptoms (Figure 15). To date, combination ICS/LABA therapy, particularly the SMART approach, appears to be an effective strategy for the prevention and management of asthma worsenings and exacerbations (Figure 16). The benefits noted with this strategy appear to be the consequence of early intervention at a very early stage of a threatened worsening (2). Furthermore, a multidisciplinary team approach involving patients, certified asthma educators, pharmacists, primary care physicians and 
specialists is likely to have the greatest impact on prevention and successful patient self-management of asthma worsenings. This approach should include regular assessment and follow-up of worsenings, individualized asthma education and goalsetting, and should include a system to identify and address potential barriers to appropriate self-management of these episodes. Regular communication among multidisciplinary team members that encourages consistent messaging, feedback and reinforcement will also be paramount for the prevention of asthma worsenings and the overall provision of care for patients with asthma.

\section{CONSIDERATIONS FOR THE FUTURE}

Given the paucity of data specific to asthma worsenings, further research on the exact causes of worsenings as well as their relationship to exacerbations and lung function decline are required. The impact of worsenings on patient QOL as well as the societal and economic costs of asthma also require further investigation. In addition, it is important to identify the exact mechanisms by which the ICS and LABA components in fixed-dose ICS/LABA combinations or the SMART approach exert their beneficial effects.

Furthermore, since asthma action plans are often underutilized by patients, some experts recommend the development of a simple yes-no response-type algorithm for patients using single-inhaler devices that outlines a step-by-step approach to the early identification and management of asthma worsenings. Such an algorithm may be as effective, but better utilized than action plans.

Other suggestions for future research include:

1. Is there a threshold number of worsenings that should prompt immediate concern and action?

2. Are some worsenings more important than others? For example, are worsenings characterized primarily by night-time awakenings more likely to lead to severe exacerbations than worsenings characterized by increased daytime rescue therapy use?

3. What other medications can effectively prevent and/or manage worsenings?

ACKNOWLEDGEMENTS: The authors thank Lorie Spence, Valear Howsam and Julie Tasso from Complete Medical Communications, whose administrative and editorial support were made possible through a grant from AstraZeneca Canada Inc.

CONFLICTS OF INTEREST: Dr Meyer Balter received honoraria for participation in consultancies and presenting educational material from AstraZeneca Canada Inc, Bayer Inc, Boehringer Ingelheim (Canada) Ltd, GlaxoSmithKline Inc, and Pfizer Canada Inc. He has also received honoraria from Merck Frosst Canada \& Co and Nycomed Canada Inc for presenting educational material. Dr Pierre Ernst received grants from AstraZeneca Canada Inc, Novartis Canada and Merck Frosst Canada \& Co for the Airway Centre at SMBD-Jewish General Hospital in Montreal, Quebec. He has also received honoraria for participation in consultancies and presenting educational material from AstraZeneca Canada Inc, GlaxoSmithKline Inc, and Merck Frosst Canada \& Co. Dr Wade Watson received honoraria for participation in consultancies and presenting educational material from GlaxoSmithKline
Inc, Nycomed Canada Inc and King Pharma. He has also received honoraria from Merck Frosst Canada \& Co and AstraZeneca Canada Inc for presenting educational material. Dr Harold Kim received honoraria for participation in consultancies and presenting educational material from AstraZeneca Canada Inc, GlaxoSmithKline Inc, Merck Frosst Canada \& Co, Nycomed Canada Inc and Schering-Plough Canada. Dr Lisa Cicutto received grants/funding from Ontario Respiratory Care Society and the Ontario Lung Association related to self management approaches of asthma. She has participated in consultancies and received honoraria from AstraZeneca Canada Inc and GlaxoSmithKline Inc for the creation of and input into asthma educational materials. Ms Marie-France Beauchesne received grant support from AstraZeneca Canada Inc (10,000CAN\$) and GlaxoSmithKline Canada Inc (10,000CAN\$) for the conduct of her research projects. She has also received honoraria for education programs presented to pharmacists from GlaxoSmithKline Inc, Boehringer Ingelheim (Canada) Ltd, AstraZeneca Inc, and Pfizer Canada Inc. She co-chairs the Astra-Zeneca Endowment Pharmaceutical Chair in Respiratory Health. Dr Andrew Cave received research funding in this therapeutic area from AstraZeneca Canada Inc, GlaxoSmithKline Inc, and Nycomed Canada Inc. He has received honoraria for participating in advisory boards from AstraZeneca Canada Inc and Nycomed Canada Inc. Dr Alan Kaplan received a grant to attend and report on findings of importance from the European Respiratory Society Meeting in Berlin in 2008. He has also received honoraria for participation in consultancies and presentation of educational material from AstraZeneca Canada Inc, Boehringer Ingelheim (Canada) Ltd, and Merck Frosst Canada \& Co. He has also received honoraria from Altana Pharma (Nycomed Canada Inc), Pfizer Canada Inc, Purdue Pharma Canada, Janssen-Ortho Inc and the Ontario Lung Association for presesenting educational material and serves on retainer with the Canadian Medical Protective Association (CMPA) as an expert witness. Ms Donna Hogg received honoraria for participation in consultancies and presenting educational material from AstraZeneca Canada Inc. Dr Andrew McIvor has received honoraria for participation in consultancies and presenting educational material from AstraZeneca Canada Inc, GlaxoSmithKline Inc, Graceway Pharmaceuticals, Novartis Canada, Nycomed Canada Inc and Merck Frosst Canada \& Co. Dr Tom Smiley received honoraria for participation in consultancies and presenting educational material from AstraZeneca Canada Inc, Boehringer Ingelheim (Canada) Ltd, Novartis Pharmaceuticals Canada, Pfizer Canada Inc and Sanofi-Aventis Canada. He also sits on the Pharmacy Advisory Board for Pfizer Canada Inc. Dr Michel Rouleau has received honoraria for participation in consultancies and presenting educational material from AstraZeneca Canada Inc, Bayer Inc, Boehringer Ingelheim (Canada) Ltd, GlaxoSmithKline Inc, Nycomed Canada Inc, Pfizer Canada Inc. He has also received honoraria for consultancies from Janssen-Ortho Inc and for presenting educational material from Merck Frosst Canada \& Co. Dr Mark FitzGerald received grant funding for asthma research paid directly to the University of British Columbia by a number of pharmaceutical companies, including AstraZeneca Canada Inc. He has also received honoraria for participation in consultancies and presenting educational material from AstraZeneca Canada Inc, Boehringer Ingelheim (Canada) Ltd, GlaxoSmithKline Inc, Merck Frosst Canada \& Co, Nycomed Canada Inc and Novartis Pharmaceuticals Canada. 


\section{REFERENCES}

1. Lemière C, Bai T, Balter M, et al., on behalf of the Canadian Adult Consensus Group of the Canadian Thoracic Society. Adult asthma consensus guidelines update 2003. Can Resp J 2004;11(Suppl A):9-18A.

2. Global Initiative for Asthma (GINA). GINA Report, Global Strategy for Asthma Management and Prevention. Update 2007. Available at: www.ginasthma.com. (Version current at April 21, 2007).

3. Chapman KR, Ernst P, Grenville A, Dewland P, Zimmerman S. Control of asthma in Canada: Failure to achieve guideline targets. Can Respir J 2001;8(Suppl A):35-40A.

4. Partridge MR, van der Molen T, Myrseth SE, Busse WW. Attitudes and actions of asthma patients on regular maintenance therapy: The INSPIRE study. BMC Pulm Med 2006;6:13.

5. Rabe KF, Adachi M, Lai CK, et al. Worldwide severity and control of asthma in children and adults: The global asthma insights and reality surveys. J Allergy Clin Immunol 2004;114:40-47.

6. Angus R, Reagon R, Cheesbrough A. Short-acting beta 2-agonist and oral corticosteroid use in asthma patients prescribed either concurrent beclomethasone and long-acting beta 2-agonist or salmeterol/fluticasone propionate combination. Int J Clin Pract 2005;59:156-62.

7. Lai CK, De Guia TS, Kim YY, et al. Asthma control in the AsiaPacific region: the Asthma Insights and Reality in Asia-Pacific Study. J Allergy Clin Immunol 2003;111:263-68.

8. Bousquet J, Boulet LP, Peters MJ, et al. Budesonide/formoterol for maintenance and relief in uncontrolled asthma vs. high-dose salmeterol/fluticasone. Respir Med 2007;101:2437-46. (Erratum in 2008;102:937-8).

9. Van Ganse E, Laforest L, Pietri G, et al. Persistent asthma: Disease control, resource utilisation and direct costs. Eur Respir J 2002;20:260-67.

10. Anis AH, Lynd LD, Wang XH, et al. Double trouble: Impact of inappropriate use of asthma medication on the use of health care resources. CMAJ 2001;164:625-31.

11. Stempel DA, Durcannin-Robbins JF, Hedblom EC, Woolf R, Sturm LL, Stempl AB. Drug utilization evaluation identifies costs associated with high use of beta-adrenergic agonists. Ann Allergy Asthma Immunol 1996;76:153-58.

12. Tattersfield AE, Postma DS, Barnes PJ, et al. Exacerbations of asthma: A descriptive study of 425 severe exacerbations. The FACET International Study Group. Am J Respir Crit Care Med 1999;160:594-99.

13. FitzGerald JM, Boulet LP, McIvor RA, Zimmerman S, Chapman KR. Asthma control in Canada remains suboptimal: The Reality of Asthma Control (TRAC) study. Can Respir J 2006;13:253-9.

14. O'Byrne PM, Bisgaard H, Godard PP, et al. Budesonide/formoterol combination therapy as both maintenance and reliever medication in asthma. Am J Respir Crit Care Med 2005;171:129-36.

15. Zhang J, Song C, Reiss TF. An endpoint for worsening asthma: Development of a sensitive measure and its properties. Drug Info J 2004;38:5-13.

16. McCoy K, Shade DM, Irvin CG, et al. Predicting episodes of poor asthma control in patients treated with asthma. J Allergy Clin Immunol 2006;118:1226-33.

17. McIvor RA, Boulet LP, FitzGerald JM, Zimmerman S, Chapman KR. Asthma control in Canada: No improvement since we last looked in 1999. Can Fam Physician 2007;53:673-77.

18. Reddel H, Ware S, Marks G, Salome C, Jenkins C, Woolcock A. Differences between asthma exacerbations and poor asthma control. Lancet 1999;353:364-69.

19. Pauwels RA, Pedersen S, Busse WW, et al; START Investigators Group. Early intervention with budesonide in mild persistent asthma: A randomised, double-blind trial. Lancet 2003;361:1071-76.

20. Price DB, Hernandez D, Magyar P, et al; Clinical Outcomes with Montelukast as a Partner Agent to Corticosteroid Therapy (COMPACT) International Study Group. Randomised controlled trial of montelukast plus inhaled budesonide versus double-dose inhaled budesonide in adult patients with asthma. Thorax 2003;58:211-6.

21. Lundbäck B, Rönmark E, Lindberg A, et al. Control of mild to moderate asthma over 1 year with the combination of salmeterol and fluticasone propionate. Respir Med 2006;100:2-10.

22. Rabe KF, Atienza T, Magyar P, Larsson P, Jorup C, Lalloo UG. Effect of budesonide in combination with formoterol for reliever therapy in asthma exacerbations: A randomised controlled double-blind study. Lancet 2006;368:744-53.

23. Kuna P, Peters MJ, Manjra AI, et al. Effect of budesonide/formoterol maintenance and reliever therapy on asthma exacerbations. Int J Clin Pract 2007;61:725-36.

24. Boulet L-P, Bateman ED, Voves R, Müller T, Wolf S, Engelstätter R. A randomized study comparing ciclesonide and fluticasone propionate in patients with moderate persistent asthma. Respir Med 2007;101:1677-86.

25. Bateman ED, Linnhof AE, Homik L, Freudensprung U, Smau L, Engelstatter R. Comparison of twice daily inhaled ciclesonide and fluticasone propionate in patients with moderate-to-severe persistent asthma. Pul Pharmacol Ther 2008;21:264-78.

26. Rodrigo GJ, Rodrigo C, Hall JB. Acute asthma in adults: A revew. Chest 2004;125:1081-102.

27. Wark PA, Gibson PG. Asthma exacerbations. 3: Pathogenesis. Thorax 2006;61:909-15.

28. Barr R, Woodruff PG, Clark S, Camargo C. Sudden onset asthma exacerbations: Clinical features, response to therapy, and 2 week follow up. Eur Resp J 2000;15:266-73.

29. Barnes PJ. Scientific rationale for using a single inhaler for asthma control. Eur Respir J 2007;29:587-95.

30. Bai TR, Vonk JM, Postma DS, Boezen HM. Severe exacerbations predict excess lung function decline in asthma. Eur Respir J 2007;30:452-56.

31. O'Byrne PM, Pedersen S, Busse WW, et al. Effects of early intervention with inhaled budesonide on lung function in newly diagnosed asthma. Chest 2006;129:1478-85.

32. Lange $P$, Ulrik CS, Scharling $H$, et al. Inhaled corticosteroids and decline of lung function in community residents with asthma. Thorax 2006;61:100-4.

33. Pauwels RA, Lofdahl CG, Postma DS, et al. Effect of inhaled formoterol and budesonide on exacerbations of asthma. Formoterol and Corticosteroids Establishing Therapy (FACET) International Study Group. N Engl J Med 1997;337:1405-11.

34. O'Byrne PM, Barnes PJ, Rodriguez-Roisin R, et al. Low dose inhaled budesonide and formoterol in mild persistent asthma: The OPTIMA randomized trial. Am J Respir Crit Care Med 2001;164:1392-97.

35. Guilbert TW, Morgan WJ, Zeiger RS, et al. Long-term inhaled corticosteroids in preschool children at high risk for asthma. $\mathrm{N}$ Engl J Med 2006;354:1985-97.

36. Covar RA, Spahn JD, Murphy JR, Szefler SJ; Childhood Asthma Management Program Research Group. Progression of asthma measured by lung function in the childhood asthma management program. Am J Respir Crit Care Med 2004;170:234-41.

37. Dijkstra A, Vonk JM, Jongepier H, et al. Lung function decline in asthma: Association with inhaled corticosteroids, smoking and sex. Thorax 2006;61:105-10.

38. Weiss KB, Sullivan SD. The health economics of asthma and rhinitis. I. Assessing the economic impact. J Allergy Clin Immunol 2001;107:3-8.

39. Malone DC, Lawson KA, Smith DH. Asthma, an analysis of highcost patients. Pharm Pract Manage Q 2000;20:12-20.

40. Hoskins G, McCowan C, Neville RG, Thomas GE, Smith B, Silverman S. Risk factors and costs associated with an asthma attack. Thorax 2000;55:19-24.

41. Lane S, Molina J, Plusa T. An international observational perspective study to determine the Cost Of Asthma eXacerbations. J Resp Med 2006;100:434-50.

42. Schwenkglenks M, Lowy A, Hanspeter A, Szucs T. Costs of asthma in a cohort of Swiss adults: Associations with exacerbation status and severity. Value in Health 2003;6:75-83.

43. Mohangoo AD, de Koning HJ, Mangunkusumo RT, Raat H. Healthrelated quality of life in adolescents with wheezing attacks. J Adolesc Health 2007;41:464-71.

44. Hong SH, Sanders BH, West D. Inappropriate use of inhaled short acting beta-agonists and its association with patient health status. Curr Med Res Opin 2006;22:33-40.

45. Lloyd A, Price D, Brown R. The impact of asthma exacerbation on health related quality of life in moderate to severe asthma patients in the UK. Prim Care Respir J 2007;16:22-7.

46. Sibbald B, White P, Pharoah C, Freeling P, Anderson HR. Relationship between psychosocial factors and asthma morbidity. Fam Pract 1988;5:12-7. 
47. van Es SM, le Coq EM, Brouwer AI, Mesters I, Nagelkerke AF, Colland VT. Adherence-related behavior in adolescents with asthma: Results from focus group interviews. J Asthma 1998;35:637-46.

48. Osman LM. How do patients' views about medication affect their self-management in asthma? Patient Educ Couns 1997;32(1 Suppl):S43-9.

49. Hyland ME, Stahl E. Asthma treatment needs: A comparison of patients' and health care professionals' perceptions. Clin Ther 2004;26:2141-52.

50. Rabe KF, Vermeire PA, Soriano JB, Maier WC. Clinical Management of asthma in 1999: The Asthma Insights and Reality in Europe (AIRE) study. Eur Respir J 2000;16:802-7.

51. Haughney J, Barnes G, Partridge M, Cleland J. The Living \& Breathing Study: A study of patients' views of asthma and its treatment. Prim Care Respir J 2004;13:28-35.

52. Aboussafy D, Balter M, Gaston G, Lavoie K, Koley S. The psychology of compromise: A focus on asthma. Canadian Thoracic Society/Lung Association, September 2004.

53. Horne R, Weinman J. Self-regulation and self-management in asthma: exploring the role of illness perceptions and treatmen beliefs in explaining non-adherence to preventer medication. Psychology \& Health 2002;17:17-32.

54. Halm EA, Mora P, Leventhal H. No symptoms, no asthma: The acute episodic disease belief is associated with poor self-management among inner-city adults with persistent asthma. Chest 2006; 129:573-80

55. Davis TC, Wolf MS, Bass PF 3rd, et al. Literacy and misunderstanding prescription drug labels. Ann Intern Med 2006;145:887-94.

56. Vincent SD, Toelle BG, Aroni RA, et al. "Exasperations" of asthma: A qualitative study of patient language about worsening asthma. Med J Aust 2006;184:451-54.

57. Lurie A, Marsala C, Hartley S, Bouchon-Meunier B, Dusser D. Patients' perception of asthma severity. Resp Med 2007;101:2145-52.

58. Cicutto LC, Ashby M. A toll free asthma helpline: Service provision and impact. J Asthma 2007;44:705-10.

59. Canadian Asthma Consensus Group. Canadian asthma consensus report, 1999. CMAJ 1999;161(11 Suppl):S1-62.

60. Boulet L-P, Bai TR, Becker A, et al. What is new since the last (1999) Canadian asthma consensus guidelines? Can Respir J 2001;8(Suppl A):3-27A.

61. Haughney J, Fletcher M, Wolfe S, Ratcliffe J, Brice R, Partridge MR. Features of asthma management: Quantifying the patient perspective. BMC Pulm Med 2007;7:16.

62. Woolcock A, Lundback B, Ringdal N, Jacques LA. Comparison of addition of salmeterol to inhaled steroidswith doubling of the dose of inhaled steroids. Am J Respir Crit Care Med 1996;153:1481-8.

63. Shrewsbury S, Pyke S, Britton M. Meta-analysis of increased dose of inhaled steroid or addition of salmeterol in symptomatic asthma (MIASMA). BMJ 2000;320:1368-73.

64. Bateman ED, Boushey HA, Bousquet J, et al. Can guideline-defined asthma control be achieved? The Gaining Optimal Asthma ControL study. Am J Respir Crit Care Med 2004;170:836-44

65. FitzGerald JM, Becker A, Sears MR, et al. A randomized controlled trial of doubling the dose of inhaled corticosteroids versus placebo in acute asthma exacerbations. Thorax 2004;59:550-6.

66. Harrison TW, Osborne J, Newton S, et al. Doubling the dose of inhaled corticosteroid to prevent asthma exacerbations: Randomized controlled trial. Lancet 2004;363:271-5.

67. Miller E, Sears MR, McIvor A, Liovas A. Canadian economic evaluation of budesonide-formoterol as maintenance and reliever treatment in patients with moderate to severe asthma. Can Respir J 2007;14:269-75.

68. Price D, Wiren A, Kuna P. Cost-effectiveness of budesonide/ formoterol for maintenance and reliever asthma therapy. Allergy 2007;62:1189-98.
69. O'Byrne PM. Acute asthma intervention: insights from the STAY study. J Allergy Clin Immunol 2007;119:1332-36.

70. Horne R, Price D, Cleland J, et al. Can asthma control be improved by understanding the patient's perspective? BMC Pulm Med 2007;7:8.

71. Revicki DA, Leidy NK, Brennan Diemer F, Sorenson S, Togias A. Integrating patient preferences into health outcomes assessment: The multi-attribute asthma symptom utility index. Chest 1998;114:998-1007.

72. Ducharme FM, Davis GM, Noya F, Rich H, Ernst P. The Asthma Quiz for Kidz: A validated tool to appreciate the level of asthma control in children. Can Respir J 2004;11:541-6.

73. Ahmed S, Ernst P, Tamblyn R, Colman N. Validation of The 30 Second Asthma Test as a measure of asthma control. Can Respir J 2007;14:105-9.

74. Ahmed S, Ernst P, Tamblyn R, Colman N. Evaluating asthma control: A comparison of measures using an item response theory approach. J Asthma 2007;44:547-54.

75. Juniper EF, Bousquet J, Abetz L, Bateman ED; GOAL Committee. Identifying 'well-controlled' and 'not well-controlled' asthma using the Asthma Control Questionnaire. Respir Med 2006;100:616-21.

76. Beasley R, Cushley M, Holgate ST. A self management plan in the treatment of adult asthma. Thorax 1989;44:200-4.

77. Boulet L-P, Bélanger M, Lajoie P. Characteristics of subjects with a high frequency of emergency visits for asthma. Am J Emerg Med 1996;14:623-8.

78. Gibson PG, Powell H, Coughlan J, et al. Self-management education and regular practitioner review for adults with asthma. Cochrane Database Syst Rev 2003;(1):CD001117.

79. Gibson PG, Powell H. Written action plans for asthma: An evidence-based review of the key components. Thorax 2004;59:94-9.

80. Toelle BG, Marks GB. The ebb and flow of asthma. Thorax 2005;60:87-8.

81. Zemek RL, Bhogal SK, Ducharme FM. Systematic review of randomized controlled trials examining written action plans in children: what is the plan? Arch Pediatr Adolesc Med 2008;162:157-63.

82. Thoonen BP, Schermer TR, Van Den Boom G, et al. Selfmanagement of asthma in general practice, asthma control and quality of life: A randomised controlled trial. Thorax 2003;58:30-6.

83. Guevara JP, Wolf FM, Grum CM, Clark NM. Effects of educational interventions for self management of asthma in children and adolescents: systematic review and meta-analysis. BMJ 2003;326:1308-9.

84. FitzGerald JM, Sears MR, Boulet L-P, et al. Adjustable maintenance dosing with budesonide/formoterol reduces asthma exacerbations compared with traditional fixed dosing: a five-month multicentre Canadian study. Can Respir J 2003;10:427-34.

85. Aalbers R, Backer V, Kava TT, et al. Adjustable maintenance dosing with budesonide/formoterol compared with fixed-dose salmeterol/ fluticasone in moderate to severe asthma. Curr Med Res Opin 2004,20:225-40.

86. Fox P, Porter PG, Lob SH, Boer JH, Rocha DA, Adelson JW. Improving asthma-related health outcomes among low-income, multiethnic, school-aged children: Results of a demonstration project that combined continuous quality improvement and community health worker strategies. Pediatrics 2007;120:e902-11.

87. Smiley T. Community pharmacist care impact on asthma management in adults. Can Pharm J 2007;140(Suppl 3):S30.

88. Mehuys E, Van Bortel L, De Bolle L, et al. Effectiveness of pharmacist intervention for asthma control improvement. Eur Respir J 2008;31:790-9.

89. Armour C, Bosnic-Anticevich S, Brillant M, et al. Pharmacy Asthma Care Program (PACP) improves outcomes for patients in the community. Thorax 2007;62:496-502. 


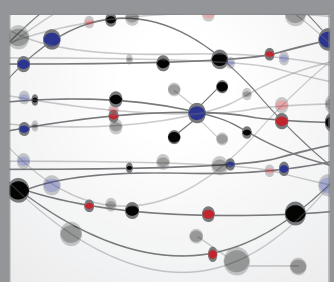

The Scientific World Journal
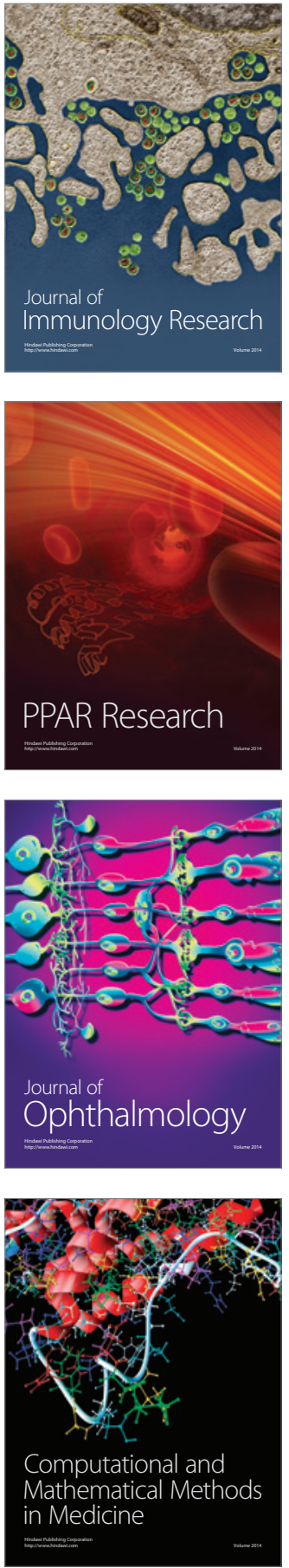

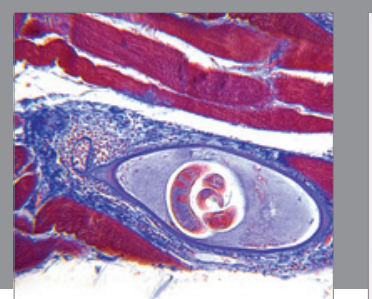

Gastroenterology Research and Practice

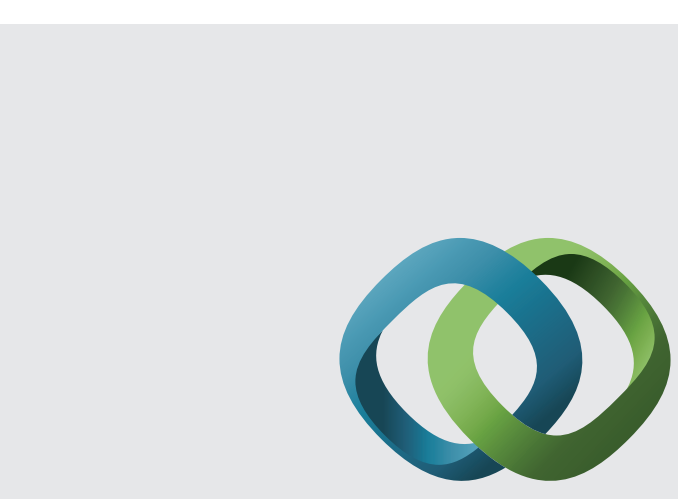

\section{Hindawi}

Submit your manuscripts at

http://www.hindawi.com
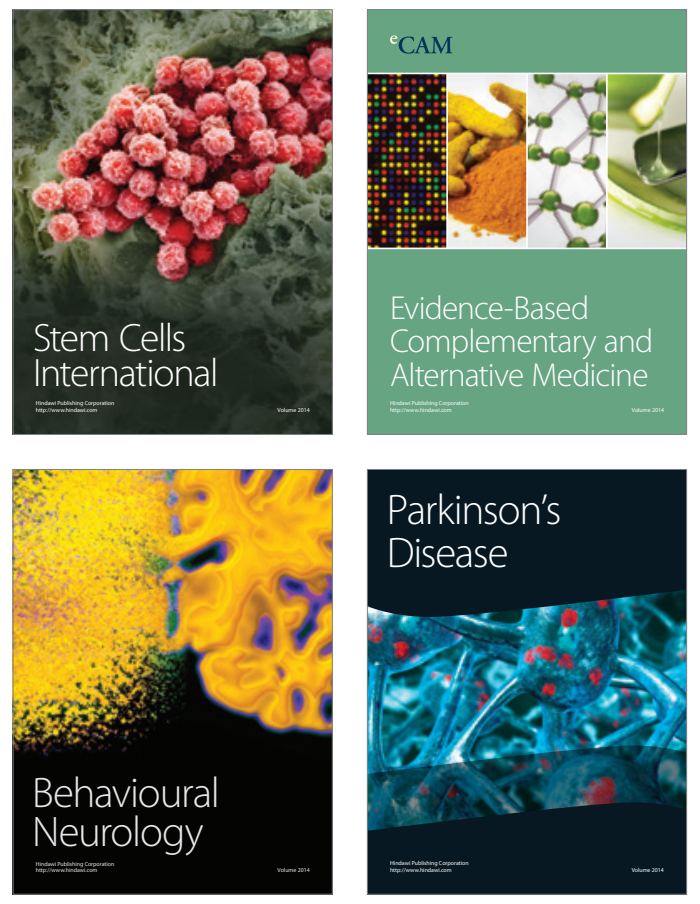
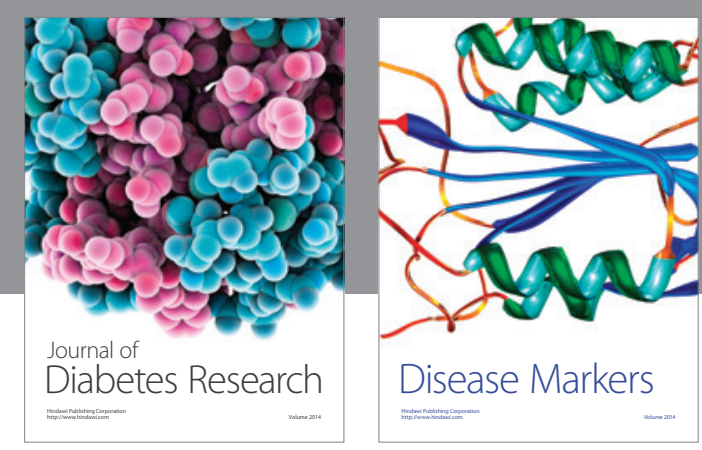

Disease Markers
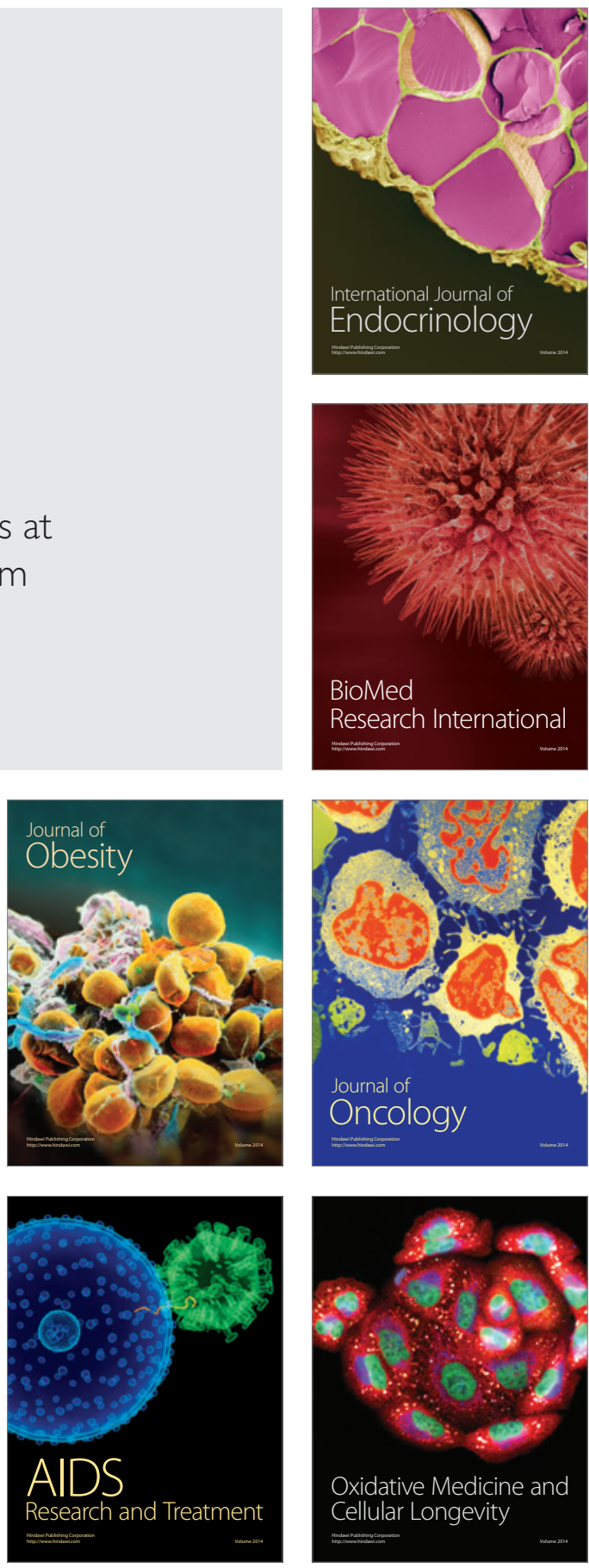